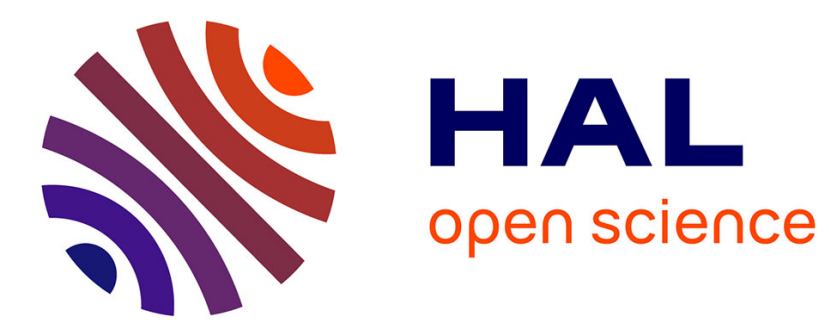

\title{
Shunjō restaurateur des principes disciplinaires au XIIIe siècle
}

\author{
Frédéric Girard
}

\section{To cite this version:}

Frédéric Girard. Shunjō restaurateur des principes disciplinaires au XIIIe siècle. Bulletin de l'Ecole française d'Extrême-Orient, 2005, 92 (1), pp.241-292. 10.3406/befeo.2005.5986 . hal-02536665

\section{HAL Id: hal-02536665 https://hal.science/hal-02536665}

Submitted on 8 Apr 2020

HAL is a multi-disciplinary open access archive for the deposit and dissemination of scientific research documents, whether they are published or not. The documents may come from teaching and research institutions in France or abroad, or from public or private research centers.
L'archive ouverte pluridisciplinaire HAL, est destinée au dépôt et à la diffusion de documents scientifiques de niveau recherche, publiés ou non, émanant des établissements d'enseignement et de recherche français ou étrangers, des laboratoires publics ou privés. 


\section{Shunjō restaurateur des principes disciplinaires au XIIle siècle} Frédéric Girard

Citer ce document / Cite this document :

Girard Frédéric. Shunjō restaurateur des principes disciplinaires au XIIle siècle. In: Bulletin de I'Ecole française d'ExtrêmeOrient. Tome 92, 2005. pp. 241-292;

doi : https://doi.org/10.3406/befeo.2005.5986

https://www.persee.fr/doc/befeo_0336-1519_2005_num_92_1_5986

Fichier pdf généré le 08/02/2019 


\title{
Résumé
}

Frédéric Girard

Shunjō restaurateur des principes disciplinaires au XIIle siècle

Le présent article est la traduction de la seconde partie de la biographie la plus fiable du moine Shunjō (1166-1227), personnage qui s'est rendu en Chine au début du XIIle siècle durant une décennie (11991211). Cette section finale de sa biographie rapporte ses faits et gestes dans la capitale, Kyōto, où il a rapporté des textes relevant de presque toutes les écoles et dispensé les enseignements qu'il avait étudiés de près sur le continent. II apparaît que l'œuvre de Shunjō répond clairement aux attentes du clergé et des autorités de son époque, en particulier celle de réformer les milieux monastiques du point de vue de la discipline. Tel avait été le but des voyages en Chine d'un religieux comme Eisai (11411215), pour ne citer qu'un exemple célèbre. La présente étude cherche à circonscrire la place et le rôle qu'a pu jouer Shunjō à partir du centre de rayonnement qu'était le Sennyūji de Kyōto où il s'était installé, et l'influence qu'il a pu exercer tant dans le clergé de Kyōto que dans celui de Nara qui sont traditionnellement concurrents et opposés. Ce personnage, dont l'œuvre écrite est pourtant très modeste, semble avoir pesé un certain poids dans l'évolution de l'histoire du bouddhisme, en raison des connaissances nouvelles qu'il apportait du continent, tant sur le plan religieux que profane, et des réactions qu'il a suscitées. C'est, par exemple, en opposition avec son éclectisme que Dōgen a voulu élaborer une forme de Dhyāna épuré et donné aux règles disciplinaires une interprétation non formaliste.

\begin{abstract}
Frédéric Girard

Shunjō, restorer of the disciplinary precepts in 13th century, Japan

This article is the translation of the second part of the most reliable biography on the monk Shunjo (1166-1227), a character who stayed in China for a decade at the beginning of the 13th century (11991211). The final section of his biography recounts his doings in the capital Kyōto, where he brought back some texts related to nearly all the different schools and dispensed his knowledge on teachings he had thoroughly studied on the continent. Shunjō's work clearly meets the expectations of the clergy and the authorities of his time, especially that of reforming the monasteries in a disciplinary perspective. Such goal was pursued by Eisai (1441-1215), a religious figure, whose travels around China provided a famous example. This study aims at defining Shunjō 's place and role in Kyōto's Sennyūji, the highly influential center where he settled, and his impact on both Kyōto's and Nara's clergy, which were traditionnally competing and opposed. Despite the limited aspect of his written work, this character seems to have carried weight in the evolution of the history of buddhism, judging from the new insights he brought from the continent - at both religious and profane levels - and from the reactions he aroused. For instance, Dōgen opposed to Shunjō's eclectism by elaborating a purer form of Dhyāna and by giving the disciplinary rules a non formalistic interpretation.
\end{abstract}




\title{
Shunjō restaurateur des principes disciplinaires au XIII ${ }^{\mathrm{e}}$ siècle
}

\author{
Frédéric GIRARD
}

\section{Introduction}

La vie, l'œuvre et les activités de Shunjō 俊芿 $(1166-1227)^{1}$ prennent place et importance à une époque où les rapports avec la Chine s'intensifiaient et où, en particulier, de plus en plus nombreux étaient les moines japonais qui se rendaient sur le Continent afin de s'enquérir des doctrines et des pratiques du bouddhisme qui y étaient en honneur. Ces moines le faisaient avec une curiosité et une avidité intellectuelles qui trouvaient leur répondant dans la hautc socićtć japonaisc, tant parmi l'aristocratie de Kyōto qu'auprès des milieux du bakufu de Kamakura, ainsi que dans les provinces, notamment celles du Sud, dans l'île de Kyūshū. À partir du milieu du $\mathrm{XIII}^{\mathrm{e}}$ siècle notamment, un afflux croissant de religieux chinois, fuyant des troubles civils, venait à son tour alimenter cette soif de connaissances nouvelles, faisant ainsi l'objet d'une rivalité entre le shōgunat et la cour de Heian, chacun des deux désirant montrer sa suprématie. Ces objectifs de prestige culturel venaient s'ajouter à des préoccupations commerciales bien plus terre à terre qui justifiaient l'envoi en Chine de vaisseaux marchands sur lesquels s'embarquaient des délégations de moines : la cour et le bakufu se mettaient ainsi en concurrence, mais aussi en congruence, à travers ces religieux qui, pour leur part, se tournaient parfois volontiers et indifféremment aussi bien d'un côté que de l'autre, en fonction de l'accueil qui leur était réservé.

1. Le présent article fait suite à celui que Charlotte von Verschuer a publié sur "Le moine Shunjô (1166-1227) : sa jeunesse et son voyage en Chine » (ci-après abrégé en Verschuer 2001). 
Un des motifs allégués pour ces voyages en Chine était la restauration des règles disciplinaires qui seraient largement tombées en désuétude depuis leur introduction officielle par le moine chinois Ganjin (Guanzhen) 鑑傊 (688-763) au milieu du $\mathrm{VIII}^{\mathrm{C}}$ siècle. En effet, les règles disciplinaires instaurées par Saichō au IX ${ }^{\mathrm{e}}$ siècle, règles dites « de bodhisattva » (bosatsukai 菩薩戒), ou encore 《 parfaites et soudaines » (endonkai 圓頓戒), mettant en principe sur un pied d'égalité clercs et laïcs, avaient gagné du terrain sous plusieurs formes, notamment dans les courants amidiques et dans les doctrines dites «de l'éveil foncier» (hongaku 本覺), qui connurent un succès grandissant, voire fort populaire, aux abords des $\mathrm{XII}^{\mathrm{e}}$ et $\mathrm{XIII}^{\mathrm{e}}$ siècles en raison des pratiques faciles, accessibles à tout un chacun, qu'elles préconisaient. On ne voit d'ailleurs guère de représentants de ces courants qui se soient préoccupés de se rendre en Chine afin de restaurer des enseignements authentiques, car le besoin ne s'en faisait pas ressentir: les doctrines qu'ils prônaient se suffisaient à elles-mêmes et suffisaient à leurs adeptes; les réformer, c'était par contrecoup les nier. Si l'on a rétrospectivement considéré la vague amidiste comme un ensemble de courants de réforme, c'est que ceux-ci étaient le fruit d'une lente maturation qui s'effectua principalement sur le sol japonais et qui, insensiblement, conduisit à des innovations sur le plan des doctrines ainsi que sur celui des pratiques religieuses: le phénomène avait pris une ampleur telle que le clergé et les autorités profanes condamnèrent à travers lui, sous leurs formes extrêmes, des dissidences ou des hérésies dangereuses surtout pour l'ordre public. De nos jours, par ailleurs, certains interprètes ont cru discerner dans ces dernières des formes authentiquement japonisées de la religion étrangère et les ont tenues à ce titre pour hautement dignes d'intérêt. En revanche, pour d'autres religieux de l'époque, soucieux de la cohérence interne de la communauté et des doctrines alors en vigueur, il était capital d'aller puiser à bonne source, en l'occurrence en Chine, pays qui fut toujours le modèle dont on voulait et pouvait tirer autorité et légitimité au Japon quand il s'agissait d'instaurer de nouvelles pratiques. C'est ainsi que, depuis l'époque de Heian (794-1185), des maîtres japonais avaient coutume de se rendre eux-mêmes sur le Continent où d'y déléguer des élèves afin de résoudre des questions litigieuses (tōketsu 肩決) tant sur le plan philosophique que pratique. C'est entre autres dans ce contexte que prend sens cette intensification de la circulation des religieux entre les deux pays qui intervient à partir du milieu du $\mathrm{XII}^{\mathrm{e}}$ siècle, au sortir de guerres civiles qui ensanglantèrent le pays et modifièrent sa configuration sociale et politique et aussi, de ce fait, ses besoins religieux. Cependant, les apports de ces voyages sont peut-être plus massifs que ceux, plus pointillistes à certains égards, des temps antérieurs - au point de changer, au moins extérieurement, le paysage religieux.

Dans quel contexte religieux global et à quels besoins répondaient ces règles restaurées et réinterprétées à la lumière des commentaires chinois ? Les deux courants du Nenbutsu 念佛 — développé par Hōnen 法然 (1133-1212) et ses disciples — et de la Darumashū 達磨宗 — la première forme du Zen, populaire à la fin du $\mathrm{XII}^{\mathrm{e}}$ siècle - sont apparus à la lisière des $\mathrm{XII}^{\mathrm{e}}$ et $\mathrm{XIII}^{\mathrm{e}}$ siècles, générant des pratiques d'aillcurs condamnées depuis l'Antiquité, mais qu'elles ont eu tendance à généraliser: ordinations privées, sans contrôle des autorités, et inclusions sans 
restriction de laïcs au sein des communautés religieuses, par le moyen de l'utilisation des «règles de bodhisattva » et d'elles seules. Ces pratiques, condamnées à plusieurs reprises en raison des désordres publics qu'elles provoquaient, allaient jusqu'à soutenir l'inutilité des règles disciplinaires et, partant, de leur observance, et même à considérer leur violation pure et simple comme n'étant pas un obstacle au salut. Mentionnons par exemple un édit de 1227 [Karoku 3], qui condamne le Nenbutsu et la secte de la Terre pure pour leurs écarts disciplinaires :

\begin{abstract}
Depuis quelques années, il est des individus qui ne respectent pas les conduites disciplinaires du Triple Joyau [dans le clergé bouddhique], qui ne prennent pas en considération les multiples édits réglementaires [dans la société civile], qui établissent le seul mot d'ordre de la " pratique exclusive » [du Nenbutsu], qui violent tous les enseignements, le leur propre et ceux des autres, qui élisent domicile à la capitale et y conduisent des individus sans repentir, ou qui se mêlant dans les forêts de montagnes y invitent des moines sans loi et qui, ce faisant, s'acoquinent avec des femmes pour se plonger dans la luxure, prennent de honteux débordements pour fondement de la voie bouddhique et font profession de proclamer la plus extrême dissipation $^{2}$.
\end{abstract}

\title{
Ou encore cet autre texte :
}

Durant l'ère Ken.ei (1206-1207), il y avait un religieux du nom de Hōnenbō. Il avait élu domicile à proximité de la capitale ; ayant établi le Nenbutsu comme une secte adoptant l'invocation du Bouddha pour principe exclusif (senshūnenbutsu 専, j:念佛), il commença à proclamer: «Il importe seulement d'invoquer le "Bouddha Amida" [Amida-butsu], sans avoir à s'adonner à quoi que ce soit d'autre, comme les services de l'exotérisme ou de l'ésotérisme ", ce qui réjouit les moniales et les adeptes laïques étonnamment stupides et ignorants. Et tandis que cette pratique se signalait par sa vaste propagation parmi ces derniers, un certain Anrakubō, un laïc qui était samurai de l'adepte laïque [Takashina Yasutsune], et qui se proclamait adepte de la pratique exclusive, a, de concert avec Jūren, professé cette pratique, déclarant que «la vénération aux six heures de la journée était une pratique du maître Shandao " (rokuji rasan wa

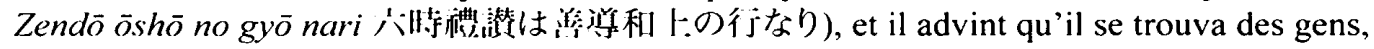
dont des religieuses, qui mirent leur foi en eux. Leur mot d'ordre finit par tant prospérer qu'à la capitale aussi bien que dans les campagnes on déclarait : « Si l'on devient un adepte [de cette pratiquc], on pourra allègrement enfreindre les règles concernant les femmes et consommer poisson et volatiles sans que le Buddha Amida vous fasse la moindre réprimande. $\mathrm{Si}$, en adoptant la pratique exclusive, on ajoute foi dans le seul Nenbutsu, à coup sûr [Amida] viendra à votre rencontre au moment de la mort. » Aussi bien, les femmes du palais de l'épouse impériale ainsi que la mère ${ }^{3} \mathrm{du}$ prince impérial entré au Ninnaji [Dōhō hōshinnō] s'en mêlèrent pour y donner leur foi et, appelant en secret Anraku[bō] et ses comparses, elles les écoutaient prêcher. Et, allant toutes du même pas à leur rencontre, il leur arrivait même d'y passer la nuit. Finalement, sans autre forme de procès, Anraku[bō] et Jūren eurent le cou tranché. Le révérend Hōnen fut chassé de la capitale comme persona non grata ${ }^{4}$.

2. Règlements juridiques [Goseibai shikimoku] (1232) de Hōjō Yasutoki, supplément du 24 du $7^{\mathrm{C}}$ mois de $1235 ; N S T$, vol. XXI, p. 140 (en note).

3. Il s'agit de Sanjō no tsubone, épouse de l'empereur retiré Gotoba.

4. Nakajima 1969, p. 520-521. 
Les Règlements judiciaires de Hōjō Yasutoki (1232), complétés par des amendements ultérieurs, s'en prennent aux abus des moines, à leur comportement contraire à la discipline bouddhique, aux autorités séculières et au bon ordre - c'est-à-dire à tous ceux qui se conduisent en tout point comme des profanes - , ainsi qu'aux ordinations « sauvages » auxquelles ils procèdent:

Article 40. Que les moines de Kamakura se disputent les fonctions ecclésiastiques à qui mieux mieux.

Étant donné qu'on perturbe l'ordre de préséance dû à l'ancienneté d'ordination par le rang de dignité ecclésiastique, on recherche de façon désordonnée à faire des promotions selon son bon plaisir et on en arrive peu à peu à accroître le nombre de dignitaires ecclésiastiques. Même un moine éminent en âge et en intelligence se trouve dépassé par un religieux puîné, comptant peu d'années en religion et dépourvu de talent. Ceci revient à renverser les ressources économiques nécessaires à la vie monastique, et à contrevenir aux principes des enseignements canoniques. Dorénavant, ceux qui sont promus se verront démis de leurs charges, s'ils sont des religieux officiant $(g u s \bar{o})$ dans les temples et les sanctuaires. Même ceux qui auront reçu le soutien [du shōgun] s'en verront également destitués. Les autres moines, comme ceux de Dhyāna (zenryo), devront recevoir des avertissements détournés de la part des conseillers ${ }^{5}$.

\section{Le même texte poursuit :}

Supplément, article 75 («Concernant les pratiquants du Nenbutsu », le 14 du $7^{\mathrm{c}}$ mois de 1235 [Bunryaku 2]) :

Chez ceux qui ont la pensée de la voie ferme, il n'y a rien à redire. Mais l'on entend dire de toutes parts qu'il en est qui consomment poissons et volatiles, qui font venir des femmes, qui forment des cliques et s'adonnent à l'envi au saké et aux festins ${ }^{6}$. Quant à ces derniers, il doit en être référé au préfet sous leur juridiction pour qu'ils soient destitués. Quant à leur personne, elle doit être chassée de Kamakura?

Le règlement suivant (article 90) s'en prend moins à la doctrine même qu'aux désordres dans la société produits par les adeptes de la Terre pure:

Ces derniers temps ${ }^{8}$, ceux qui, sous le nom d'adeptes du Nenbutsu, revêtent la toge noire, affluent à la capitale et dans les provinces, font intrusion en tous lieux et se distinguent parfois par leur conduite dissipée. Il importe plus que tout d'y mettre le holà. Il convient de régler l'affaire en fonction de ce qui a été édicté dans le Kantō [par le bakufu]. De tels agissements ont fait l'objet d'édits à de multiples reprises ${ }^{9}$, mais il n'y a pas encore été remédié, et il importe

5. NST, vol. XXI, p. 30 .

6. Dans ses Recommandations en sept articles [Shichikajō seikai 七籍條制誡], Hōnen réprimandait sévèrement ses adeptes qui consommaient de la chair animale, buvaient du saké et s'adonnaient à la luxure, conscient qu'il était que de tels comportements donnaient prétexte aux autorités de réprimer les tenants de la Terre pure. Voir infra l'annexe III,p. 283.

7. Nakajima 1969, p. 139.

8. NST, vol. XXI, p. 140.

9. Le premier de ces édits fut celui de 1207 [Ken.ei 2], qui condamnait le Nenbutsu et la secte (voir supra p. 243, cité dans l'édit de 1227 [Karoku 3], et infra p. 246). 
de rendre à nouveau des édits en tout lieu et d'en informer le conseiller en second Nijō [Sadataka] ${ }^{10}$, selon l'ordre à exécuter.

Le 24 du $7{ }^{\mathrm{e}}$ mois de 1235 [Bunryaku 2]".

Cet article critique aussi la cession de charges monastiques à des moines qui ne sont pas habilités ou encore à des laïcs (article 97) :

Quand les moines officiant dans les pavillons monastiques [de Kamakura] tombent malades, ils cèdent leur charge à des disciples incompétents ou chutent dans le monde en plaçant un prêtenom ${ }^{12}$, et en outre ils convoitent des profits indus. Mis à exécution par les fonctionnaires appointés par le préfet de Hyōgo, le 7 du $12^{\mathrm{c}}$ mois de 1238 [Ryakunin 1].

Dans un cas ou dans l'autre, ils contreviennent de toute façon au sens du bouddhisme. Céderaient-ils leur place en tant que maîtres, ils n'auraient pas pour autant à délivrer des autorisations à des individus non habilités. Même dans le cas d'une personne de discernement supérieur, il est interdit d'user d'une cession consentie par un religieux dissipé. Dorénavant, il faut observer fermement les injonctions et faire une cession en choisissant des personnes aux capacités sortant de l'ordinaire, et qui s'adonnent exclusivement aux conduites selon les règles sans jamais y contrevenir ${ }^{13}$.

Rappelons quelques dates qui marquent les événements :

1175: Hōnen (1133-1212) proclame la pratique exclusive du Nenbutsu (fondation de la secte de la Terre pure [Jōdoshū]).

1186: À Ōhara, une controverse aurait opposé Hōnen à des moines du Hieizan et de Nara.

1189: Le grand chancelier (kanpaku) Kujō Kanezane 九條兼實 (1149-1207) protège le Jōdoshū de Hōnen.

1190: Hōnen lit les trois textes canoniques de la secte de la Terre pure au Tōdaiji de Nara.

1194: Interdiction de la Darumashū.

1198: Pour clarifier sa position, Hōnen rédige son Recueil sur le choix exclusif (Senchakushū 選擇集); Eisai 榮西 (1141-1215) publie son Traité sur la protection du pays par l'avènement du Dhyāna (Kōzen gokokuron 興禪護 国論) pour se démarquer de la Darumashū.

1199: Shunjō se rend en Chine.

1202: Pratique de la Commémoration de Śākyamuni (Shaka nenbutsu 釋迦念 佛) par Jōkei 貞慶 (1155-1213) au Tōshōdaiji. Fondation du Kenninji par Eisai. Kanezane se fait religieux sous Hōnen.

1204: Le Hieizan condamne le Nenbutsu de Hōnen ( $10^{\mathrm{e}}$ mois) ; Recommandations en sept articles (Shichikajō seikai 七箇條制誡) de Hōnen ( $11^{\mathrm{e}}$ mois) et intervention de Kanezane auprès du Hieizan.

10. Ce personnage est peut-être lié à Kujō Michiie, qui officiait dans le Kantō à cette époque. (voir $N S T$, vol. XXI, p. 126 et note).

11. Ibid., p. 140.

12. Vivent comme des profanes en établissant un supérieur de monastère à titre purement nominal.

13. NST, vol. XXI, p. 140. 
1205: Jōkei : Supplique du Kōfukuji (Kōfukuji sōjō 與福寺奏上.), dirigée contre le Nenbutsu exclusiviste (Senju-nenbutsu).

1207: Interdiction du Senju-nenbutsu, exil de Hōnen à Tosa et de Shinran 親愁啋 (1173-1262) à Echigo. Mort de Kanezane, principal soutien de Hōnen.

1208: Un ami de Jōkei, Myōe 明惠 (1173-1232), lui aussi opposé à l'exclusivisme amidique, lit des extraits du Senchakushū de Hōnen.

1211: Retour au Japon de Shunjō.

1212: Mort de Hōnen ( $1^{\mathrm{cr}}$ mois). Myōe publie son Zaijarin 推邪輪, critique du Senchakushū $\left(11^{\mathrm{e}}\right.$ mois).

1213: Nouvelle critique du Senchakushū [Shōgonki 莊嚴記] par Myōe $\left(6^{\mathrm{e}}\right.$ mois $)$.

1220: Jien 慈圓: Mes humbles vues [sur l'histoire du Japon] (Gukanshō 愚管 抄).

1224: Shinran fonde l'Ikkōshū 一向宗 (futur Jōdo Shinshū 淨士畺宗) et commence à rédiger le Kyōgyōshinshō 教行信證.

1225: Myōe restaure la coutume de prêcher les règles [sekkai 説戒].

1227: Interdiction du Nenbutsu par la cour ( $7^{\mathrm{e}}$ mois).

1232: Le régent Hōjō Yasutoki 北條泰恃 (1183-1242) promulgue les Réglements juridiques (Goseibai shikimoku 御成敀式目) du bakufu.

1235 : Interdiction du Nenbutsu par le bakufu.

Il va de soi que les autorités et le clergé bouddhique ont cherché à contrecarrer les tendances laxistes qui se faisaient jour et entraient en contradiction ou en conflit direct avec les principes les plus évidents du bouddhisme, parmi lesquels venait en premier la nécessité de concevoir la pensée de l'éveil. Les réactions varièrent entre le rejet et la condamnation purs et simples et, d'autre part, des accommodements d'autant plus concevables que la pratique de conférer les « règles de bodhisattva » s'était largement répandue parmi l'aristocratie de Heian. Elles s'accompagnèrent cependant d'une volonté d'instaurer un système d'ordination des religieux fondé sur une conception cohérente des règles disciplinaires. On chercha donc à restaurer dans leur intégralité les systèmes jadis en vigueur. Néanmoins, les échanges accrus avec le Continent conduisirent à penser qu'on pouvait prendre pour modèle les systèmes d'ordination de la Chine, dans la mesure où ce pays en avait instauré de nouveaux, encore inconnus au Japon, concernant certains aspects touchant les pratiques. Pour les Japonais, le système était celui d'une double ordination, d'une part selon les deux cent cinquante règles à respecter pour les religieux et, $d$ 'autre part, selon les « règles de bodhisattva », ce double système étant synthétisé dans le "triple ensemble de règles pures "; s'y ajoutaient les rites de repentir et la « retraite double » (en été et en hiver). Le modèle chinois faisait référence, mais pouvait parfois aussi constituer un contre-exemple lorsqu'il entrait en contradiction avec les pratiques japonaises: sur le Continent, l'ordination plénière impliquant le respect des deux cent cinquante règles était une condition sine qua non pour devenir religieux, et l'imposition des règles de bodhisattva venait seulement coiffer cette ordination pour lui insuffler l'esprit du Grand Véhicule, à l'aide d'interprétations de détail différant d'école à 
école. C'est cette conception des règles que les partisans du rigorisme voulurent réimplanter au Japon. Cependant, elle ne faisait pas l'unanimité puisque, selon le sens que l'on donnait à l' "esprit des règles », le respect stricto sensu des deux cent cinquante règles était susceptible de souffrir d'écarts d'interprétation. Cela était d'autant plus probable que l'observance pointilleuse et littérale des règles était ellemême considérée comme un manquement au code disciplinaire, et que le système d'ordination instauré par Saichō au début du IX siècle a pu être compris comme ne requérant a priori pas cette observance. À preuve de cette différence entre les pratiques chinoise et japonaise, on peut mentionner le fait que, lorsque des moines japonais se présentaient en Chine, il leur fallait être porteurs d'un certificat d'ordination attestant qu'ils avaient bien reçu l'ordination plénière, soit au Tōdaiji soit dans l'un des deux autres centres officiels d'ordination qui existaient en province, formalité dont ils s'acquittaient parfois à la hâte, presque à la veille de leur départ. L'exemple de Dōgen (1200-1253) reste célèbre à cet égard, qui ne s'était pas muni d'un tel certificat pour se rendre en Chine.

C'est ici que les voyages d'Eisai (1141-1215) en Chine prennent une bonne partie de leur sens. Eisai tenait à se démarquer des adeptes de la secte de Bodhidharma (Darumashū), qui y voyait un avatar laxiste du Zen. Un jour qu'on lui demandait ce qui caractérisait cette secte, il répondit ainsi :

QuestION. - Un certain personnage [disciple de Dainichi Nōnin] se prévaut de la secte Zen sous le nom frauduleux de secte de Bodhidharma. Et il soutient de son propre chef: «Il n'est ni pratique ni culture [qui compte en soi]. Les passions n'existent pas à l'origine, elles sont par définition l'éveil. C'est pourquoi il n'y a pas à faire usage des règles disciplinaires [les défenses

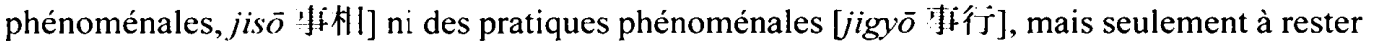
couché. Pourquoi s'éreinter à pratiquer la commémoration des bouddhas, à faire offrande de reliques, à faire des jeûnes prolongés ou à manger maigre ? » Que penser de ces assertions ?

RÉPONSE [d'Eisai]. - Ce sont des gens qui ne sont pas sans accomplir de mal ${ }^{14}$. C'est ce que dans les enseignements saints ${ }^{15}$, on appelle une vue entachée de vacuité. On n'a ni à discuter ni à s'asseoir à côté de telles gens. Il faut s'en écarter de cent yojana ${ }^{16}$.

Le même reproche de laxisme disciplinaire est fait à propos de la secte de Bodhidharma par des témoins contemporains, tel Myōe, qui affirme: "Le Dhyāna de Bodhidharma pêche par excès d'abstractionnisme 17. " Aussi cette secte est-elle particulièrement néfaste pour les laïcs, toujours selon lui : «En outre, ce qu'on qualifie, entre autres noms, de secte de Bodhidharma n'a pas de raison de convenir aux

14. Sütra du filet de Brahmā [Fanwangjing 梵網經], $19^{\mathrm{C}}$ règle des 48 règles légères, $T S D$, vol. XXIV, $n^{\circ} 1484$, p. 1006 b.

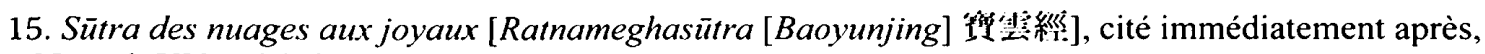
$T S D$, vol. XVI, n ${ }^{\circ} 658$, p. $278 \mathrm{c}$.

16. Traité sur la protection du pays par l'avènement du Dhyāna [Kōzen gokokuron 興潬護回国論] (1198), NST, vol. XVI, p. 41.

17. Commentaire oral à la Signification doctrinale du germe de la foi selon l'Ornementation fleu-

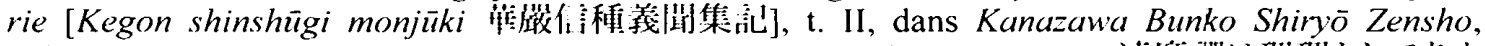

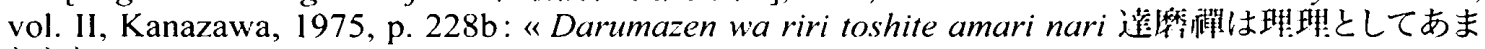
りなり。》 
laïcs ${ }^{18}$. \ En effet, la secte de Bodhidharma, par son subitisme, se projette directement dans la nature des choses, dans l'immuable, et en arrive de ce fait à nier la causalité :

À propos de la phrase «L'eau ne peut pas [produire] seule des vagues. Il faut que ce soit en raison du vent que les vagues se produisent », Girinbō [Kikai] déclare : "Quand on dit qu'un drapeau bouge, est-ce le vent qui bouge ou est-ce le drapeau ? Ce n'est pas le drapeau seul qui est en action, mais c'est toujours en raison du vent [qu'il y a mouvement]. Ce n'est pas le vent seul qui est en action, mais c'est toujours en raison du drapeau [qu'il y a actualisation d'un mouvement]. Si le drapeau était seul en action, il devrait se mouvoir lors même qu'il n'y aurait pas de vent. Si le vent seul était en action, on devrait entrevoir des signes de mouvement même s'il n'y avait pas de drapeau. Ainsi donc, il devrait de toutes les façons y avoir déploiement d'activité. Mais l'absence de mouvement est une absence de mouvement du drapeau. Tel est le sens de l'assertion selon laquelle il n'y a pas de choses en dehors de la nature de la pensée. Le mouvement est la motion du vent. CEuvrer ainsi en regard de choses qui se meuvent, on appelle cela ne pas œuvrer. C'est pourquoi, au fondement de l'absence de mouvement, se trouve toujours compris le mouvement. Et au fondement du mouvement, se trouve toujours impliqué le nonmouvement. L'école de Bodhidharma de l'enseignement soudain se borne à pénétrer dans la nature de ce qui n'est pas en mouvement et ne juge pas des signes distinctifs. Sous le nom d'éveil soudain et de réalisation abrupte, le point névralgique est certes profond.

Question. - On ne pourra dès lors plus voir les myriades de choses soumises à la coproduction conditionnée?

RÉPONSE. - Lorsqu'on regarde la coproduction conditionnée, à partir de quoi entret-on ? Selon le Traité des maitres de yoga, " Si, en prenant connaissance de la vérité de l'égalité du principe unique on nie la causalité de la production conditionnée dépendante d'autrui, on tombera dans le reproche d'une cohabitation [du mouvement du phénoménal et de l'immobilité du principiel] sans association conjointe [des deux]. "C'est parce qu'on rejette la causalité qu'on se trouve en dehors de toute possibilité de jugement [comme les tenants de l'école de Bodhidharma] ${ }^{19}$.

Selon Myōe, c'est en effet le subitisme qui entraîne le rejet de la causalité dans cette secte:

Que l'éveil soudain dans la première pensée selon le Sütra de l'Éveil parfait [Yuanjuejing [国堅經] est libéré des quatre maladies.

Les quatre maladies dont on est libéré selon le texte du sūtra. - Lorsque, ayant réalisé la nature de l'éveil parfait, on entre en concentration, on a une efficacité égale à celle d'un bouddha. C'est pourquoi on est dégagé de la maladie sous ses quatre aspects. En général, dans la secte de Bodhidharma, ceux qui cultivent cette méthode d'examen [de la nature de l'éveil parfait] ne distinguent pas entre la nature des choses et leurs qualités. Et lorsqu'ils ne sont plus entrés en examen, ils arrêtent toute élaboration à l'égard des choses bonnes ou mauvaises, et rejettent toute action ; c'est un vice de croire être ainsi soudainement arrivé [à cette nature d'éveil parfait]. Comme la nature de l'éveil parfait est sans marque de pensée différenciée, au moment où l'on examine, on coupe court à toutes vues fausses ou mauvaises qui soient différenciées et on suit cette nature. Or, au moment où l'on est sorti d'examen mental aussi, à tout moment la pensée est tournée vers cette nature. Aussi, comme tous les actes bons sont fidèles à cette nature, on

18. Notes pour prévenir l'oubli [Kyakuhai bōki 却廃忘話] $\mathrm{n}^{\circ} 44$ (MSS, vol. II, p. 550).

19. Commentaire oral au Commentaire fondamental sur le Traité sur l'acte de foi dans le Grand Véhicule [Kishinron honsho chōshūki 起信論本疏聴集記] (DNBZ). 
les cultive, [alors que], tous les actes mauvais entrant en contrariété avec elle, on les arrête. On appelle cela aussi, parmi les trois sortes d'examens mentaux, la pratique d'égalisation. C'est un vice de tous les enseignements parfaits et soudains que, dans la première pensée, on réalise tout d'abord la nature de l'éveil qui existe originellement et que dans l'action on annule le début et la fin [de la carrière du bodhisattva], se rendant ainsi égal au stade du fruit. C'est pourquoi on enjoint dès le début d'écarter les quatre maladies et de se séparer des quatre marques [temporelles] ${ }^{20}$.

C'est le besoin de démarquer le Zen de la secte de Bodhidharma, qu'il ne cesse de critiquer, qui conduit Myōe à associer cette école au Japon aux règles disciplinaires. À travers le Zen, il s'agit pour Eisai de restaurer les règles et d'entamer une réflexion nouvelle sur leur conception. Il s'en fait le porte-parole, tout au long de son Traité sur la protection du pays par l'avènement du Dhyāna, dans des dialogues fictifs ou réels ainsi qu'en faisant appel à un nombre considérable de citations. Donnons quelques exemples:

Question. - Quelqu'un a avancé la critique: «Pour quelle raison la secte proclamet-elle à nouveau qu'elle fait perdurer la Loi ?"

RÉPONSE [d'Eisai]. - Ce sont les règles disciplinaires qui sont la norme qui fait perdurer la Loi. En l'occurrence, ici, cette secte Zen a pour principe les règles disciplinaires. C'est pourquoi son serns est de faire perdurer la Loi ${ }^{21}$.

Question. - Pourquoi la secte Zen enjoint-elle à toute force de s'adonner aux pratiques disciplinaires?

RÉPONSE. - C'est dans le sens où on manifeste la pérennité du nirvāna en prenant les règles pour adjuvants. Le Sūtra des derniers enseignements [Yijiaojing 遺教經] 22 déclare: " C'est grâce aux règles qu'on fait naître le dhyāna qui produit la sapience ${ }^{23}$. "; " C'est sur ces fondements [textuels] que cette secte prend les règles disciplinaires pour son début et le dhyāna pour sa fin. Si une personne qui a violé les règles porte un coup d'arrêt au mal avec une pensée de repentir, il méritera le nom d'homme du dhyāna. À combien plus forte raison s'il réside dans la pensée de grande compassion développera-t-il immanquablement toutes les qualités disciplinaires ainsi que l'intelligence sapientielle. C'est pourquoi cette secte prend pour fondement la grande compassion. Quelles fautes ne détruirait-elle pas ${ }^{24}$ ?

20. Récits de Toganoo [Toganoo onmonogatari 栂尾御物語], DNBZ, vol. XLII, p. 475a (sermon du 15 juin 1220). Sur cette secte à l'époque de Kamakura, voir Niikura Kazufumi 新倉和文, La secte de bodhidharma et ses détracteurs [Darumashūto sono hihanshatachi 達磨宗とその批判者達], IBK, 33[2], mars 1985, p. 106-107; Takahashi Shūei 高橋秀栄, Matériaux historiques sur Dainichi Nōnin et la secte de Bodhidharma (II) [Dainichi Nōnin to Darumashū ni kansuru shiryō 大日能仁と達魔 宗に関する史料[II]], Kanazawa Bunko Kenkyū 金澤沢文庫研究, 22[7] - 23[1], décembre 1976janvier 1977, p. 21-33 ; et Bernard Faure, «The Daruma-shū, Dōgen and Sōtō Zen », Monumenta Nipponica, 42[1], 1987, p. 25-55. Selon les Histoires qui sont maintenant du passé [Konjaku monogatari 今昔物語], vol. XX, histoire n³4, c'est Saichō qui aurait introduit la Darumashū.

21. Közen gokokuron, NST, vol. XVI, p. 35.

22. Citation approximative de $T$, vol. XII, nº 389, p. 1111 a.

23. Kōzen gokokuron, NST, vol. XVI, p. 36 .

24. Ibid., p. 37. Voir aussi p. 43 : "C'est sur ces fondements [scripturaires] que la secte Zen accorde la priorité aux règles disciplinaires. » 
D'après une lettre d'Eisai, le courant Rinzai (Linji) du Zen chinois auquel il a été initié mettait en œuvre le Code disciplinaire en Quatre Sections, c'est-à-dire les règles plénières indiennes des Dharmaguptaka, aussi bien que les « règles de bodhisattva » $\operatorname{sinisées}^{25}$. C'est pourquoi, selon lui :

Dans la réception des défenses, les règles du Grand Véhicule et celles du Petit Véhicule résident dans les dispositions mentales de celui [qui les reçoit] et consistent seulement à concevoir la pensée de grande compassion pour apporter profit aux êtres. Ici, cette secte [Zen] n'opte exclusivement ni pour les règles du Grand Véhicule ni pour celles du Petit Véhicule ; elle tient uniquement en estime l'observance des pratiques ascétiques.

Ces règles sont aussi bien celles du moine que du bodhisattva, et ont à être prêchées tous les quinze jours, coutume tombée en désuétude qu'Eisai a voulu remettre en honneur, ainsi que l'a fait par ailleurs $M y \bar{o} e^{26}$ :

Dans l'observance des règles, si, après avoir reçu l'ordination, on ne les respecte pas et on les viole, en quoi cela différerait-il d'avoir obtenu une gemme précieuse pour la briser ? C'est pourquoi on doit observer fermement les deux cent cinquante règles des religieux ainsi que les trois ensembles de règles, les dix défenses graves et les quarante-huit règles légères « de bodhisattva », et les prêcher tous les demi-mois pour les expliquer aux fidèles selon les exposés des sütra disciplinaires. Si quelqu'un viole les règles, il doit être exclu. Il en est comme de l'océan qui ne retient pas les cadavres dans son fond ${ }^{27}$.

Eisai veut aussi restaurer les pratiques du jeûne prolongé et des repas maigres, ainsi que l'observance disciplinaire au cours d'exercices journaliers ${ }^{28}$. De même veut-il que, sur le modèle de la Chine, les religieux pratiquent les deux retraites annuelles, en été et en hiver, qui depuis longtemps n'étaient plus observées au Japon ${ }^{29}$. Dōgen reste dans cette ligne de conduite mais il n'a pas cherché à combattre ces nouvelles sectes - en l'occurrence celle de Bodhidharma - sur le strict terrain des conceptions disciplinaires, se contentant de formuler un système très succinct et schématique fondé sur les règles « de bodhisattva ».

C'est dans ce contexte que s'inscrit le voyage de Shunjō, et l'accueil qui lui fut réservé à son retour de Chine indique bien que la lutte contre le laxisme disciplinaire et les ordinations "sauvages » était au centre des préoccupations. Sa biographie accorde une large place à l'accueil qu'il trouva auprès du clergé de Nara, autour de la personne de Jōkei, ou de celui de Heian, autour de celle de Jien, mais aussi des

\section{Ibid., p. 55.}

26. Myōe organisa des séances de prédication des règles à partir du sixième mois de 1225 : le fait pourrait refléter l'influence de Shunjō, qui se serait exercée par l'intermédiaire de Jōkei, lequel était un ami de Myōe. Voir Girard 1990, p. 101-102.

27. Közen gokokuron, NST, vol. XVI, p. 81 .

28. Ibid., p. 81-82.

29. Ibid., p. 83 . 
hauts personnages de la noblesse de Kyōto, voire de Kamakura. Les récits concernant Tokudaiji Kintsugu 徳大寺公継 (1175-1227) et surtout Kujō Michiie 九條道 家 (1193-1252) sont particulièrement développés et significatifs. Ils indiquent aussi la pluralité des besoins religieux : outre les règles, la foi dans la Terre pure d'Amida, les doctrines du Tendai et l'ésotérisme. Le récit biographique fait également place aux vertus confucianistes qui, associées ou non au bouddhisme, auraient permis à certains de ces personnages de remplir leurs fonctions avec bonheur et réussite. L'enseignement des règles disciplinaires semble ici associé à un besoin de redressement moral, mettant tout naturellement en avant les doctrines confucianistes. La mention de ces dernières, et en particulier la référence à un mot de Confucius qui fait de la régulation de la personne individuelle la condition du développement des capacités humaines dans les affaires du gouvernement ${ }^{30}$, semble indiquer pourquoi on a ressenti la nécessité de restaurer les règles bouddhiques : la biographie nous renseigne sur les attentes à l'égard des doctrines et des pratiques introduites de Chine par Shunjō ; les préoccupations semblent en effet surtout politiques et sociales. Elle nous présente également un paysage, somme toute assez complet, des croyances et des usages qui avaient cours au Japon.

Mais faisons un court retour sur la question disciplinaire. On peut globalement distinguer quatre types de règles disciplinaires alors en vigueur au Japon, qui pouvaient se combiner selon les occurrences et les types de carrières monastiques envisagés.

1. Tout d'abord, les règles proprement cléricales, qui étaient entérinées par les autorités et dispensées sur les estrades d'ordination du Tōdaiji à Nara et du Kanzeonji à Daizaifu ainsi que dans le Kantō. Ce sont les règles complètes (gusokukai 具 足戒), qui étaient considérées nécessaires pour entrer dans l'état de religieux. Elles avaient pour origines les vinaya indiens en "Quatre Sections" [ch. Shifenlu, jap. Shibunritsu 四分律] traduits, interprétés et élaborés en système par le grand théoricien Daoxuan [Dōsen] 道宣 (596-667) de Nanshan (Nanzan 南l!], respectueux des deux cent cinquante préceptes destinés aux moines et des cinq cents préceptes regardant les moniales ; elles étaient appelées pour cette raison Vinaya en Quatre Sections (Sifenlu, Shibunritsu 四分律) ou Vinaya de Nanzan (ch. Nanshanlu, jap. Nanzanritsu 南山律).

2. Viennent ensuite les « consécrations » [kanjō 灌頂] propres à l'ésotérisme, délivrées par un " maître » (ajari 阿闍梨), qui habilitent un ordinant à devenir à son tour «maître ». Ce sont celles qui, dans l'école Shingon, étaient délivrées au Kōyasan, sur une estrade d'ordination spécifique. Mais elles étaient combinées avec les règles plénières du Tōdaiji en raison des liens étroits qui avaient dès l'origine existé entre le Kōyasan et ce dernier temple ${ }^{31}$. Le Tendai ésotérique avait ses «consécrations » propres, associées aux règles parfaites et soudaines et aux règles " de bodhisattva » du Hieizan et, le cas échéant, à celles, complètes, reconnues au Tōdaiji.

30. Entretiens de Confucius [Lunyu], XIII, 13.

31. Sur ces règles telles qu'elles avaient été définies par Kukai 'ct: 游 (774-835), voir l'annexe III, infra p. $283-284$. 
3. Avaient également cours les préceptes faisant partie intégrante de l'enseignement parfait du Grand Véhicule (daijō engyo 大乘潰教), règles en principe reconnues par toutes les écoles du Grand Véhicule, en particulier par celles de l'école gnoséologique Hossō, du Kegon, du Tendai et du Ritsu. Elles font appel à deux ensembles de textes. Le premier ensemble textuel professe «trois ensembles de règles pures " (sanju jōkai 三聚淨戒), à savoir les interdictions strictes (ritsugikai 律儀戒), les préceptes préconisant de cultiver le bien pour soi-même (shōzenpōkai 攝善法戒) et ceux qui incitent à faire le bien à autrui (shōshujōkai 攝 毷生戒) ${ }^{32}$; le Vinaya de Daoxuan ignore cette tripartition, ne connaissant que le premier ensemble de règles ${ }^{33}$, mais l'école Ritsu japonaise issue de Ganjin s'efforcera de les intégrer, non sans quelque artifice exégétique. Les seconds se fondent en premier lieu sur un apocryphe chinois, le Sütra du filet de Brahmā (Fanwangjing 梵網經), qui a eu une valeur œcuménique et a été reconnu par presque toutes les écoles, notamment le Sanron, le Hossō, le Kegon, le Tendai et le Ritsu. Ce sūtra, qui professe des « règles de bodhisattva » (bosatsukai 菩薩戒) à travers l'existence de dix interdictions graves et de quarante-huit fautes légères, ignore la tripartition des préceptes précédente mais plusieurs écoles, dont celle du Ritsu, ont cherché à établir un système de correspondance en identifiant les dix interdictions graves aux dix défenses strictes, celles concernant le bien pour soi-même aux quatre-vingtquatre mille rubriques de la Loi traditionnellement reconnues, et celles touchant le bien altruiste aux quatre pensées immenses (bienveillance, compassion, joie et détachement) ${ }^{34}$.

Ces deux ensembles de textes prétendaient être les porte-parole des préceptes du Grand Véhicule et c'est de manière toute naturelle qu'on a cherché à les rapprocher et à les combiner entre eux, d'une part, et aussi, d'autre part et pour des raisons historiques, avec les règles du Vinaya en Quatre Sections qui, elles aussi, prétendaient en Chine comme au Japon appartenir au Grand Véhicule ${ }^{35}$.

Ces préoccupations tenaient à la façon de présenter le trinôme définissant le chemin bouddhique: la moralité (kairitsu 戒律, skt. śilla), la concentration mentale (zenjō 樿定, skt. dhyāna) et la sapience (chie 智慧, skt. prajñā). Selon la tradition la plus ancienne, chaque élément de ce trinôme est la condition d'apparition du suivant; mais selon les perspectives les plus radicales du Grand Véhicule, le stade ultime est atteint dès la première étape. Pour ce faire, on avançait l'idée

32. En particulier en s'appuyant sur le Traité des terres des maîtres de Yoga (Yogacārabhūmiśāstra), (TSD, vol. XXX, n 1579, p. $511 \mathrm{a})$.

33. Il n'établit une correspondance - et dans un sens très particulier - qu'entre les trois groupes de règles pures et les trois corps de Buddha (respectivement de la Loi, de rétribution et de correspondance). Voir Signification de la prise de refuge dans la doctrine bouddhique [Shimen guijingyi 釋門䆏 敬儀], TSD, vol. XIV, n 1896, p. 856b.

34. En s'appuyant sur un passage du Sütra sur les ornementations du bodhisattva [Pusa yingluo benyejing 苦薩啰樂珞本栄經] $\left(T\right.$, vol. XXIV, $n^{\circ} 1485$, p. 1020c-1021b), texte qui lui aussi est un apocryphe.

35. Les Règles en Quatre Sections, étant celles de la secte des Dharmaguptaka, appartiennent par définition au Petit Véhicule, mais les scoliastes du Kitsu, à commencer par Daoxuan, y ont reconnu des traits altruistes propres au Grand Véhicule (voir son Commentaire des actes du Vinaya en Quatre Sections (ZZ, I, 64, p. 433 A-1). 
d' une « essence », d'une « nature en soi » ou d'un « corps » des règles (kaitai 戒體), qui ne se résolvait pas en une simple « intention » ( $i$ 意) de contrer le mal et d'accomplir le bien mais devait également se concrétiser par des actes sensibles du corps (shin 身) et de la parole ( $k u$ 口), autrement dit «s'incarner » (tai 體) dans l'action et le comportement. En faisant dans ce domaine appel aux doctrines de l'école gnoséologique, Daoxuan devait voir dans cette « essence disciplinaire » des germes de bien plantés dans la conscience-de-tréfonds par suite du "parfumage » (c'est-à-dire de l'imprégnation) ${ }^{36}$ des pensées erronées inconscientes par la pensée de bien conçue lors de la réception des préceptes. Mais, selon lui, ces germes sont une « incarnation des règles » dans la mesure seulement où ils agissent en acte et en substance sur la conscience superficielle ${ }^{37}$. Dans ces conditions, les deux autres éléments du chemin, à savoir la concentration mentale, qui fixe et unifie la pensée sur un objet ( $s h i$ 此), et la sapience, qui discerne correctement les dharma (kan 觀), sont des mises en œuvre sublimes de la conscience seule et, à ce titre, sont déjà inclues dans le premier élément, c'est-à-dire la discipline. Selon les perspectives de la doctrine parfaite, la discipline, qui est déjà porteuse de la concentration et de la sapience, est en conséquence, telle quelle, la force décisive qui donne l'impulsion à la culture de ces deux autres éléments ; sans elle, ils resteraient sous l'emprise de l'erreur. Si l'on pousse jusqu'à son terme cette conception des choses, on en arrivera à considérer qu'il n'est aucun élément qui ne ressortisse à la discipline et que les trois éléments en question fusionnent et s'interpénètrent parfaitement pour former un tout indissociable ${ }^{38}$. C'est cette logique de pensée - qui lie de manière indissoluble théorie et pratique, intelligence et œuvres - qui se trouve au fond de presque tous les courants réformateurs de l'époque de Kamakura qui ont voulu lutter contre les mouvements laxistes de l'école de Bodhidharma de Dainichi Nōnin et de la Terre pure se réclamant de Hōnen.

4. Enfin, les écoles Zen avaient pour leur part élaboré des règles disciplinaires spécifiques qui se fondaient sur les Règles pures de Baizhang (Hyakujō shingi 百 丈清規). Partant en guerre contre les écoles seulement « doctrinales », qui privilégient la sapience, elles veulent mettre l'accent sur la pratique — en l'occurrence la méditation, certes, mais aussi sur les valeurs du travail manuel, travail interdit par tous les Vinaya -, et ce afin de réformer de l'intérieur un clergé qui se montrait trop dépendant des donations des laïcs et pour cette raison tendait à se corrompre. Le texte même des règles de Baizhang est aujourd'hui perdu, mais on connaît la devise de ce personnage singulier, passée en proverbe: «Un jour sans travail, c'est

\footnotetext{
36. Concernant le terme vāsanā et sa traduction, on trouve bien, en dehors d'imprégnation, le mot "parfumage ", chez un auteur solide, Louis de La Vallée Poussin, dans sa traduction française de la Vijñaptimātratāsiddhi, T. XXXI, n 1585, p. 43a10-45c5, LVP, p. 473-475: « parfumage » (LVP): l'action d'une cause qui n'a pas d'effet immédiat (pas hetupratyaya), mais qui reste latente et n'est donc que condition rectrice (adhipatipratyaya); il est l'exhalaison (qifen 氣分 / qifen 釆分) de l'acte, et est produit par imprégnation ( $x i=x u n x i$ 熏習). Siddhi, T. XXXI, n 1585, p. $43 \mathrm{a}^{8-17}$; LVP, p. 473475).
}

37. Ibid. (ZZ, I, 64, p. 430 A-1); Épitomé de l'école Ritsu [Risshūkōyō 律宗綱要] (T, vol. LXXIV, p. 1lb).

38. C'est le point de vue soutenu surtout par le Tendai, qui identifiera par ailleurs ces trois éléments du chemin aux trois vérités que sont, selon lui, la vacuité, le provisoire et le milieu. 
un jour sans mangeaille » (Ichinichi nasazareba ichinichi kurawazu 一日作らざれ ば一日食わず). Au Japon, plusieurs types de règles ont eu cours, mais nous n'en mentionnerons que deux tendances. Tout d'abord celle d'Eisai, pour qui le Dhyāna n'est autre que les règles mêmes ${ }^{39}$, mais qui associe les règles du Zen non seulement avec les règles complètes, mais aussi avec l'onction de l'ésotérisme. Ce courant devait être largement suivi dans les écoles Zen, tous courants confondus, même au-delà du Rinzai. La prégnance des pratiques de l'ésotérisme parmi toutes les couches de la population ne fut apparemment pas étrangère au succès de ce syncrétisme, qui peut paraître insolite. L'autre tendance est celle de Dōgen, qui tout en soutenant que le Dhyāna est indissociable des règles, accorde la précellence au premier sur les secondes. Il a élaboré un système de préceptes singulier, fondé sur un rigorisme intégral et dénué de tout élément ésotérique. Ce sont ses règles en seize articles: les trois premières sont celles du Triple Refuge (dans le Buddha, la Loi et la communauté), les trois groupes de préceptes purs qui s'inspirent de la tradition du Tendai, et dix interdictions graves dont la liste et certains intitulés semblent propres à Dōgen.

Dans ce paysage, Shunjō occupe une position qui, malgré son absence visible de particularité, n'en demeure pas moins importante. On ne lui connaît aucune appartenance sectaire stricte ; tout au plus l'historiographie bouddhique lui a-t-elle concédé, un siècle après sa mort, la qualité de restaurateur du Ritsu de Kyōto à laquelle on ne saurait cependant le réduire. Il participe de tous les courants en vogue à son époque au Japon : le Shingon, le Tendai, l'ésotérisme, le Zen, l'amidisme. Son principal mérite est d'avoir introduit un nombre considérable de textes relatifs à tous ces courants, parmi lesquels des commentaires du Vinaya par Lingzhi

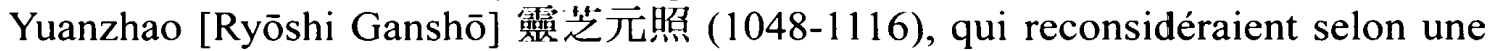
ligne orthodoxe l'interprétation qu'avait systématisée Daoxuan, mais en l'infléchissant clairement dans le sens d'une valorisation des règles " de bodhisattva " selon l'enseignement parfait du Tendai et en y adjoignant la foi en Amida. Yuanzhao, grand restaurateur chinois de l'école disciplinaire et Shunjō, avait eu l'occasion d'étudier trois années auprès de Ru'an Lianghong 如菴了宏(?-?), qui appartenait à la lignée de Yuanzhao. C'est l'apport de ces textes, et aussi de pratiques nouvelles auxquelles son long séjour en Chine lui avait permis de s'initier, qui attira sur lui l'attention du clergé mais aussi des milieux aristocratiques de Kyōto. La particularité la plus saillante de ses conceptions disciplinaires est, dit-on, qu'il préconisait la réception commune des «trois ensembles de règles communes pures 》 (sanju tsūkai 三聚通 戒), qui s'étaient surtout diffusés parmi le clergé de Nara, et l'auto-ordination (jisei bikukai 自誓比丘戒), qui s'était répandue parmi celui de Kyōto. Shunjō concevait l'auto-ordination comme une ordination plénière, et son usage devait s'en limiter aux seuls cas où l'on ne pouvait trouver les dix maîtres requis pour la conférer en public: il ne voyait pas en elle, comme cela était le cas de l'ordination commune chez les moines de la tradition de Nara, tel Kakujō, un idéal de bodhisattva qui serait conféré au récipiendaire. Mais, de fait, il est parfois malaisé d'assigner des frontières strictes à son influence, s'agissant de la diffusion de ses doctrines ${ }^{40}$.

39. Traité sur la protection du pays par l'avènement du Dhyāna, NST, vol. XVI, p. 43.

40. Minowa 1999, p. 100-101. 
Mentionnons le cas de Jōkei, moine issu du Kōfukuji qui s'enquit des règles disciplinaires auprès de Shunjō. Jōkei n'avait étudié que le Traité sur la pratique du Vinaya en Quatre sections de Daoxuan, car au Japon on ignorait les autres ouvrages de Daoxuan, tels le Commentaire sur les règles disciplinaires ${ }^{41}$, le Commentaire sur les actes ${ }^{42}$ et le Traité sur le sens du Vinaya ${ }^{43}$. Dès que Shunjō fut revenu de Chine, Jōkei envoya son disciple Kainyo Chisokubō ${ }^{44}$ 戒如知足房 chez Shunjō afin de l'interroger sur des questions pendantes touchant le Sifenlu xingshizhang [Shibunritsu gyōjishō⿴囗儿口分律行事鈔] de Daoxuan ${ }^{45}$. Shunjō lui donna alors le commentaire de cet ouvrage composé par Yuanzhao, le Sifenlu xingshizhao zijiji [Shibunritsu gyojishō shijiki 四分律行事鈔資持記], ce qui permit à Jōkei de dissiper tous ses doutes ${ }^{46}$. Grâce aux nouvelles interprétations qu'il contribua à faire connaître, Shunjō fut à l'origine du mouvement de renouveau disciplinaire de Nara impulsé par les figures de Kakujō 覺盛 (1193-1243), Eison 豰尊 (1201-1290) et Enshō 圓 照 $(1221-1277)^{47}$. Il semble pourtant que ceux-ci n'aient jamais admis l'idée que les trois ensembles de règles pures suffisaient, à eux seuls, à conférer l'état de religieux, comme l'avait soutenu Onkaku 恩覺 (actif en 1162), un moine du Kōfukuji, dans un ouvrage qui fit date à Nara mais ne subsiste qu'à l'état de fragments, le Traité sur l'expulsion du faux et la promotion du vrai dans le degré de supériorité des règles des capitales du Sud et du Nord [Nanboku kairitsu shōretsu kengi kōshinshō 南北 戒律勝劣遣俘䀧眞章 ${ }^{48}$.

41. Commentaire fondamental annoté sur les règles disciplinaires des moines selon le Vinaya en Quatre Sections [Sifenlu biqiuhanzhu jiebenshu 四分律比丘含注戒本䟽] ( $T$, vol. XL, nº 1806).

42. Il s'agit du Commentaire sélectif circonstancié sur les actes selon le Vinaya en Quatre Sections [Sifenlu shanbu suiqi jiemo shu 叫分律随機羯磨疏], composé en 648 (ZZ, I, 64, 3-5, p. 260-510).

43. Traité collectant le sens du Vinaya selon le Vinaya en Quatre Sections [Sifenlu shipini yichao V4分 律拎堒龙義鈔], composé en 627 (ZZ, I, 71, 1, p. 30-73).

44. Moine du Saidaiji, élève de Jōkei qui lui enseigna le Hossō et les règles disciplinaires (biographie dans Biographies des moines éminents au Japon [Honchō kōsōden 本朝高僧傳], LVIII [DNBZ, vol. CIII, p. 287]). Il était réputé pour être versé dans la discipline aussi bien du Petit que du Grand Véhicule. Il eut pour émules Kakujō 覺盛 du Tōshōdaiji, Yūgon 有嚴 du Saihōin, Enjō [圆暗 du Fukūin, Eison 敋桨 du Saidaiji, Zenkan 樿観, Zen.e 禪慧 et Gonshun 踇俊 du Tōdaiji, Kakuchō 舅淡 du Chisokuin, et Keison 継尊 du Hōtōin.

45. Titre complet: Traité sélectif sur les pratiques du Vinaya en Quatre Sections [des Dharmaguptaka]

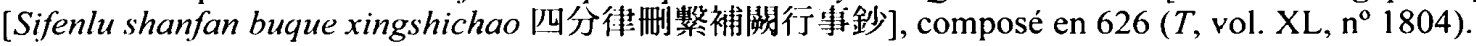

46. Le fait est rapporté dans le Traité des arcanes de Gankyū de Matsuyama [de la province de Bicchū] (Shōzan Gankyū Tetteishō 松山元休徽底章), chapitre Règles d'auto-ordination pour les moines à Nara (NDZ, vol. LXIX, p. 249c), cité par Tokuda Myōhon, « Le maître de discipline Shunjō et le code disciplinaire de Nara », dans Ishida 1972 (éd.), p. 66-82, spéc. p. 69 et n. 13. Shunjō a dû également faire connaître les deux autres commentaires de Yuanzhao, le Jiebenshu xingzongji 戒本䟽行少䛎 et le Jiemoshu jiyuanji 羯磨疏濟縁記. De son séjour en Chine, il rapporta en tout 327 volumes de textes disciplinaires.

47. Biographie dans Biographies du Joyau des moines du jardin du Vinaya [Ritsuen sōböden 律范僧空率 傅], XII (DNBZ, vol. CV, p. 266); Honchō kōsōden, LVIII (DNBZ, vol. CIII, p. 303-306); et les Actes

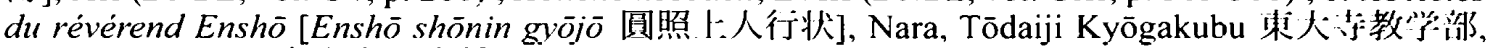
Tōdaiji Toshokan 東大寺仪暂館, 1977.

48. Mentionné par Minowa 1999, p. 77-79. 
À Kyōto, Shunjō chercha à perpétuer et à développer la tradition du Tendai de cumuler une pluralité d'enseignements dans le même temple. C'est ainsi qu'il voulut perpétuer au Sennyūji l'étude du Vinaya, mais aussi celles de l'enseignement parfait du Tendai, de l'ésotérisme, du Zen et de la Terre pure ; c'est également dans la perspective du Tendai - qui consiste à faire état d'enseignements provisoires de circonstance afin d'indiquer la vérité ultime - qu'il préconisa la pratique du Vinaya en Quatre Sections en la subordonnant au point de vue des règles du Grand Véhicule telles que les définit le Sütra du Filet de Brahmā. Certains de ses disciples, tels Shinkai 心海 ${ }^{49}$ (actif en 1229-1232), Chikyō 智鏡 ${ }^{50}$ ou Tankai 湛海 ${ }^{51}$, devaient se rendre en Chine pour poursuivre l'œuvre accomplie par leur maître au Sennyūji. Parmi les héritiers de Shunjō à Kyōto dans le domaine des règles disciplinaires, on peut compter le moine Jōgō 淨業 (1173-1259), qui se rendit en Chine, trois années après le retour de Shunjō, étudier les règles disciplinaires auprès de Tieweng Shuyi 鐵翁守一, un disciple de Ru'an Lianghong, pour établir un temple disciplinaire, le Kaikōji 戒光寺, au sud de Kyōto en $1228^{52}$. C'est à partir de ce temple que le moine Jōin 淨因 (1217-1221) ${ }^{53}$ devait déployer une activité considérable pour répandre les idées de Yuanzhao, aussi bien à Kyōto qu'à Nara, où il fut le maître en discipline de Gyōnen 凝然 (1240-1321), et dans la région de Kamakura, à Sagami. Mentionnons le nom d'Enrin Ichijōbō 㖽淋一乗房 (1174-?), un disciple d'Eisai (1141-1215) au Kenninji, dont il fut le huitième supérieur, et qui avait étudié le Tendai auprès de Shōshin Hōchibō 證眞寶池房 (actif en 1186-1204) et de Shunjō. Il est l'auteur d'un Commentaire sur le sens des règles du Tendai [Tendai kaigi shoshō 天台戒義疏鈔] composé en 1237 en se référant fréquemment aux thèses de Shunjō - plus d'une trentaine de fois - et qui a longtemps servi de manuel dans l'école. Il est le principal restaurateur des règles parfaites et soudaines du Tendai au Kenninji qui, dans l'esprit d'Eisai, restent associées à la doctrine parfaite du Tendai et à l'ésotérisme ; c'est dans ce même Kenninji que Shunjō avait d'ailleurs résidé quelque temps à son retour de Chine et avait peut-être initié Dōgen aux règles disciplinaires. Que cette transmission ait effectivement eu lieu ou non, ce dernier semble en tout cas en avoir retiré un sentiment de rejet pour toute forme de ce syncrétisme que Shunjō pouvait incarner: Dōgen devait recommander le respect des « règles de bodhisattva ", en se refusant à y adjoindre un quelconque élément d'interprétation supplémen-

49. Pour des éléments biographiques sur Shinkai, voir infra n. 116.

50. Biographie dans Ritsuen sōbōden, XI (DNBZ, vol. CV, p. 253-254) ; et dans Honchō kōsōden, LVIII (DNBZ, vol. CIII, p. 288).

51. Biographie dans Ritsuen söböden, XI, DNBZ, vol. CV, p. 254; et dans Honchō kōsōden, LVIII (DNBZ, 103, p. 286-287). Tankai se rendit en Chine en 1235-1238, d'où il rapporta une relique, une dent d'ivoire du Buddha, qu'il entreposa au Sennyūji. L'histoire de cette relique est rapportée dans le Récit de la transmission de la dent du Buddha au Sennyūji de Higashiyama à Kyōto [Rakuyō Tōzan

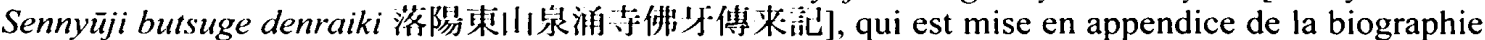
de Shunjō (version de Tenpō). Ce document est présenté dans Girard 2005, p. 163-170.

52. Biographie dans Ritsuen sōbōden, XI (DNBZ, 105, p. 252) ; et dans Honchō kōsōden, LVIII (DNBZ, 103 , p. 284-285).

53. Sur ce personnage, voir Honchō kōsōden, LVIII (DNBZ, 103, p. 288b). 
taire, pas même celui de «l'essence disciplinaire » chère à la tradition japonaise. Élève d'Enrin et auteur de plusieurs ouvrages, Kakukū Jūjibō 覺空十地房 s'est attaché à restaurer les règles au Manjuji 萬壽寺 de Kyōto. Il s'est montré héritier non seulement de son maître, mais également de Ben.en 辨圓 (1201-1280), du Tōfukuji, moine du Rinzai qui enseignait la pratique concurrente de l'enseignement parfait, de l'ésotérisme - issu du courant d'Eisai et de son disciple Eichō 榮朝 (?-1247), du Chōrakuji 長樂寺 de Kamakura -, du Zen et des règles ; il était également héritier d'un disciple de Hōnen, Tankū Shōshinbō 湛空正信房 (11761253), du Nison.in 二尊院 de Saga 嵯峨, à Kyōto, qui essaya d'associer l'esprit des règles disciplinaires aux enseignements de la Terre pure. Cette association des règles à la doctrine de la Terre pure, telle que l'envisageait Yuanzhao, a été marquée par Gyōnen, ce qui indique qu'elle a été perçue comme une innovation à son époque: Gyōnen a connu les enseignements de la Terre pure transmis par Shunjō grâce au moine Chōsai 長西 (1184-1266), dont il a écouté la prédication au Kubonji 九品寺 de Kyōto ${ }^{54}$.

Ces filiations de Shunjō à Nara et à Kyōto, ici seulement esquissées jusqu'à la première ou à la deuxième génération, montrent que son apport a été notable, quoique discret, par l'introduction des idées disciplinaires de Yuanzhao, considérées comme nouvelles au Japon, et par l'association de ces idéaux disciplinaires à la pratique et à l'étude de courants de pensée comme l'ésotérisme, l'exotérisme, le Zen ou la Terre pure. Toujours est-il que, en partie sans doute grâce à son influence, l'étude des règles fleurissait dans les deux grandes villes durant l'ère Katei [1235$1238]^{55}$. C'est la combinaison de ces divers éléments - ainsi que les pratiques concrètes et les textes de référence - qui caractérise les courants envisagés. Pour s'en tenir à la seule question disciplinaire, on peut avancer, sans trop risquer de se tromper, que la tradition de Nara a, dans son ensemble, assigné aux « règles de bodhisattva » et aux trois ensembles de règles pures une place importante mais en fin de compte subsidiaire : selon lui, elles permettent de conférer au récipiendaire le statut de bodhisattva (personnage qui s'adonne en particulier à des œuvres sociales), mais pas celui de moine à part entière. La tradition du Hieizan reconnaîtra dans son enscmblc la prévalence des "règles de bodhisattva » sur les autres, mais avec des différences de détail.

S'étant en outre lié avec des disciples de Zhu Xi, dont Yang Jian 楊筒 ${ }^{56}$, qui avait réussi à devenir docteur aux examens, Shunjō passe également pour être le premier introducteur au Japon du confucianisme des Song. Jusqu'alors, seul était connu le confucianisme de la tradition des Han, qu'étudiaient des familles spécialisées dans

54. Il s'agissait d'un cours sur le Commentaire au Sūtra de la Méditation sur Amitāyus [Guan Wuliang-

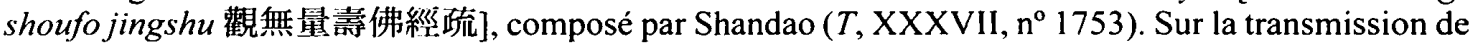
la doctrine de la Terre pure de Lingzhi Yuanzhao par Shunjō, doctrine associée au Vinaya et au Tendai, voir le Sangoku buppō denzūengi : 國佛法傳通縁起 [Historique de la transmission de la Loi bouddhique dans les Trois Pays] de Gyōnen (DNBZ, 105, p. 101).

55. Voir la biographie de Jōshun dans le Honchō kōsōden (DNBZ, 103, p. 285).

56. De façon directe ou indirecte, Shunjō semble avoir connu en tout cinq disciples de Zhu Xi. Voir Verschuer 2001, p. 180-181 et n. 91 . 
ce domaine, et sans doute est-ce avec Shunjō qu'a débuté, dans les temples Zen dits "des Cinq Montagnes » [Gozan 五山] la coutume de recueillir et de transmettre les interprétations nouvelles de Zhu Xi et de ses précurseurs. Sur le seul plan disciplinaire, Shunjō passe autant pour un restaurateur du Ritsu de la tradition de Kyōto que de celui de Nara. Sa relative indétermination et son éclectisme sectaires pourraient expliquer l'accueil très favorable que lui fit Eisai à son retour de Chine, tout autant que celui que lui réserva Jōkei de Nara, si l'on en croit sa biographie. Dans le premier cas, une affiliation d'origine plutôt liée au Hieizan, la volonté d'intégrer des éléments ésotériques dans les doctrines et les pratiques ainsi qu'une expérience commune en Chine suffisaient à rapprocher les deux hommes. Dans le second, c'est la volonté de rénover par des interprétations nouvelles la tradition du Ritsu du courant de Nanzan, qui semble être à l'origine des liens entre Shunjō et Jōkei, bien que rien ne les rapprochât au départ. Mais Shunjō est sans doute aussi en bonne partie à l'origine d'une réaction négative, comme par exemple celle de Dōgen, qui l'avait eu comme maître en discipline au Kenninji de Kyōto mais se rattachait à un courant qui se refusait à adjoindre de l'ésotérisme ou les pratiques de la méditation amidique à un dhyāna qui se voulait épuré.

Shunjō a intéressé ses contemporains par ce qu'il leur apportait de nouveau, mais comme il n'avait pas la personnalité ni l'aura d'un fondateur de secte, il n'a ni fait l'objet d'une hagiographie ni de légende notable. La biographie qu'on a de lui, composée peu après sa mort, malgré les traits hagiographiques habituels dans ce genre de document, offre un grand degré de fiabilité. C'est ce qui fait l'un de ses intérêts. Elle a été reprise dans des recueils biographiques ultérieurs, qui y ajoutent des éloges, et ses activités sont mentionnées anecdotiquement dans certains ouvrages ${ }^{57}$. Aussi n'a-t-il laissé que très peu d'ouvrages doctrinaux - encore s'agit-il pour la plupart de textes à usage interne de la communauté —, si bien que son influence ne peut guère se mesurer à travers la littérature bouddhique. C'est, semble-t-il, surtout son enseignement qui a marqué ses disciples et auditeurs qui, de proche en proche, l'ont transmis de génération en génération, ainsi que l'attestent leurs biographies. En raison de ses liens avec l'aristocratie de Kyōto, l'empereur Gokomatsu lui a conféré le titre posthume de «maître national Daikōshōbō» (daikō shōbō 大與 正法國師) en 1411, l'empereur Meiji celui de 《grand maître Gachirin »(月輪大 師) en 1883, et plusieurs empereurs ont honoré sa mémoire. On peut dire que son influence n'est guère allée au-delà de ces manifestations, qui entraînèrent cependant des réfections périodiques du Sennyūji, qu'il avait restauré. C'est plutôt le rôle historique qu'il a joué au sein de la communauté bouddhique de Kyōto qui retiendra ici notre attention.

La biographie de Shunjō que nous présentons, la Biographie du maître de la Loi Fukaki du Sen.yūji [Sen.yūji Fukaki hōshi den 泉涌封不可车法師傳], en un volume, a été rédigée par le moine Shinzui Kyōsaibō 信瑞敬西房 (?-1279) en 1244 (Kangen 2), sur la demande que Jōshun lui en fit en 1243, date qui correspond au dix-septième anniversaire de la mort de Shunjō. Shinzui devait avoir alors une qua-

57. Voir Partie I Verschuer 2001, Introduction. Voir aussi infra l'Éloge, p. 276-278. 
rantaine d'années et c'est sans doute sa renommée de savant qui incita les disciples de Shunjō au Sen.yūji, alors en plein essor, à faire appel à lui ${ }^{58}$. Shinzui était un moine Jōdo de Kyōto qui semble avoir été d'abord élève de Ryūkan 隆寛 (11481227), un disciple quelque peu dissident de Hōnen sur le plan disciplinaire, puis être devenu un disciple de Shinkū Hōrenbō 信空法蓮房 (1146-1228), un autre fidèle de Hōnen. Il a rédigé un Recueil des sons et des sens des trois sūtras de la Terre pure [Jōdo sangyō ongishü 浄土三部経音義集], en quatre volumes (1235, premier mois), un Recueil de résolution auspicieuse des vastes doutes [Kōgi zuiketsushū 廣 疑瑞決集], en cinq volumes (1256, huitième mois), une célèbre Biographie illustrée du saint Genkū fondateur de la secte de la Terre pure [Jōdoshü Genkū shōnin.e 淨土宗源空_上.人繪], également appelée Biographie du saint de Kurotani [Kurotani shōninden 黑谷上人傳], en un volume, qu'il présenta lui-même au régent Hōjō Tokiyori 北條時頼 (1227-1263) en 1262 (Kōchō 2) à Kamakura, et un Recueil sur l'éclaircissement du sens et la progression de la pratique [chez les disciples de Hōnen] [Myōgi shingyōshü 明義進行集] en trois volumes ${ }^{59}$, ouvrage fort lié au précédent. Shinzui avait donc la réputation d'être un bon auteur de biographies et d'avoir recueilli de façon détaillée et de première main les témoignages doctrinaux des premiers disciples de Hōnen. Le Myōgi shingyōshū fait en particulier état de la biographie et de la foi dans la Terre pure de huit religieux qui se rallièrent à la pratique de l'invocation orale du nom d'Amida sans l'appui de la méditation, c'està-dire en gardant telle quelle la « pensée dispersée » (sanshin 散心) ${ }^{60}$, telle que la préconisait Hōnen ${ }^{61}$. Sans doute a-t-on jugé qu'il était bien placé pour accomplir un travail de ce genre pour Shunjō, bien que celui-ci ait été partisan des pratiques méditatives de la commémoration du Buddha. D’après son propre témoignage, il semble avoir connu Shunjō de près.

On connaît différentes versions de cette biographie :

- la version originale de 1244 (perdue);

- la version de Kan.ei (Kan.ei 19, soit 1642), [ZGSRJ, vol. IX[1], p. 45-58], ciaprès abrégée en $K$;

- la version de Tenpō (Tenpō 15, soit 1844), [version du Sennyūji (Sennyūjibon)

58. Fujita 1972, p. 282-283.

59. L'ouvrage a un colophon du moine Eban 恵鐡, daté du $22^{\mathrm{e}}$ jour du 5 mois de 1283 (Kōan 6), soit quatre années après la disparition de Shinzui. Le premier volume, qui devait porter sur Hōnen, manque.

60. Sanshin: il s'agit ici de l'esprit non concentré de l'homme, qu'il soit clerc ou laïc, dans la vie profane.

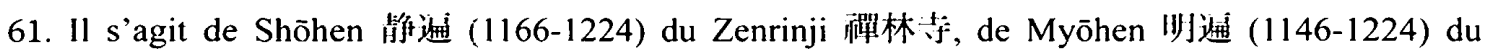

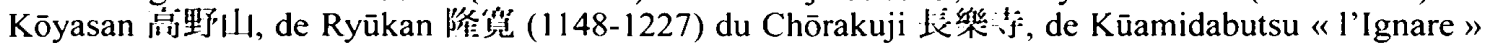

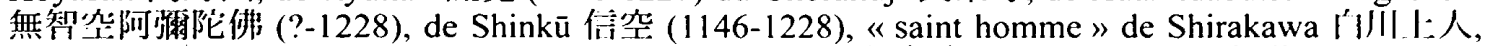

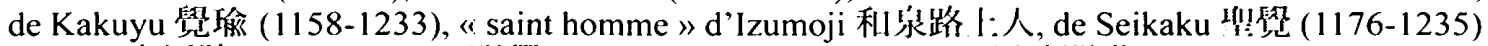

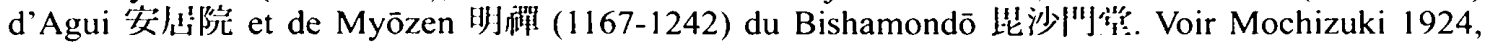
p. 1-6; et Ōtani Daigaku Bungakushi Kenkyūkai 2001. 
reproduite dans Ishida 1972 (éd.), p. 411-420]. J'ai également utilisé une autre version, manuscrite, du Sennyūjibon, indatable (fin Edo-début Meiji ?), qui porte des signes de lecture et propose des lectures de caractères, parfois utiles, qui datent de 1883 [Meiji 16] au plus tôt. Elle comporte en appendice le récit de La transmission de la dent du Buddha au Sennyūji. Elle m'a été procurée par l'épouse du regretté Tanaka Hisao, que je tiens à remercier ici. [Cette version est abrégée ci-après en $T$ ])

- la version de Hōreki (Hōreki 7, soit 1757) du Kunaishō (Kubon) [DNBZ, 115 , p. 519-535, qui est collationnée avec la version de Tenpō du Sennyūji [Senbon]], ci-après abrégée en $H$.

Notre traduction ne mentionnera pas certaines variantes textuelles, dénuées d'intérêt.

\section{Traduction}

Biographie du maître de la Loi Fukaki du Sennyūji.

[... \e 23 du $4^{\mathrm{e}}$ mois de la même année [1211], il [Shunjō] entra à la capitale et se rendit directement au Kenninji. Le doyen [Eisai] ${ }^{62}$ ainsi que les adeptes du Dhyāna s'assemblèrent comme des pigeons dans le jardin ${ }^{63}$ et s'alignèrent tels des canards au portail ${ }^{64}$ pour l'accueillir alors qu'il pénétrait dans la cellule du supérieur $^{65}$, faisant brûler de l'encens et saluant ce dernier. Il séjourna là quelque temps et l'ensemble des moines étudia sous sa conduite.

Le $10^{\mathrm{e}}$ mois, l'hiver de la $2^{\mathrm{e}}$ année de Kenryaku [1212], il s'installa au Sūfukuji — connu sous son appellation courante de « Stūpa d'airain d'Inari Kaerizaka ${ }^{66}$ ».

62. Chōrō lét老: «le (ou les) doyen(s)». Eisai est mentionné en qualité de doyen du Jufukuji de Kamakura en 1199 (Shōji 1). le $15^{\mathrm{e}}$ jour du $7^{\mathrm{e}}$ mois, selon l'Azuma kagami [Miroir des provinces de l'Est] 吾势鏡, mais non pas de doyen du Kenniji. $H$ et $T$ portent $s \bar{j} \bar{o}$, (《recteur monacal »): Eisai fut recteur monacal seulement au sixième mois de 1213, selon l'Azuma kagami, mais le biographe de Shunjō lui donne déjà ce titre, de façon rétrospective. Dans tous les cas, il semble hors de doute qu'il s'agisse d'Eisai. Sur les problèmes que pose sa titulature, voir Taga 1972, p. 132.

63. $T$ ajoute ici : «pour l'accueillir ».

64. $T$ conclut le paragraphe ici, avec « pour le révérer ».

65. «Le supérieur » : il s’agit d'Eisai.

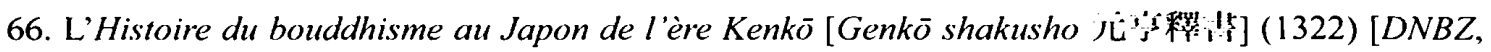
101, p. 293] précise que c'est parce que le monastère possédait dans son enceinte un monument en bronze commémoratif du Buddha (caitya) qu'on parlait familièrement de "Stūpa d'airain ». S'agiraitil du Sūfukuji d'ōmi, situé entre le Hieizan et l'Onjōji, qui fut semble-t-il incendié par les moines du mont Hiei et de l'Onjōji en 1163, à la fin de l'époque de Heian ? Au xx xiècle, un reliquaire remarquable (trésor national) a été découvert sur l'emplacement des vestiges du stūpa. On a émis l'hypothèse

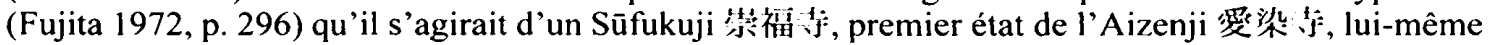
associé au grand sanctuaire d'Inari situé à Kyōto, dans le quartier de Fushimi. C'est le temple où vivait le supérieur du sanctuaire depuis la fin du Moyen Âge (Anzu et Umeda 1968, p. 53). On pourrait penser dans ce cas que l'appellation de Sūfukuji aurait été donnée par Shunjō en souvenir de celle d'un monastère où il avait séjourné en Chine. Sur les liens entre Aizen et Inari, voir Frank 2000, p. 86. 
L'été de la $2^{\mathfrak{c}}$ année de Kenpō [1214], le commentateur Dugu Yuncui ${ }^{67}$ remit au moine Ryōyū ${ }^{68}$, en partance pour le Japon, un portrait du maître Beifeng ${ }^{69}$. Par ailleurs, le maître en discipline Dōjō du Keifukuji lui [à Shunjō] fit don d'un bol, qui est l'un du millier de bols en fer qu'avait fait fondre jadis le grand roi Jian pour en faire offrande à un millier de moines ${ }^{70}$.

Au printemps de la $5^{\mathrm{e}}$ année de Kenpō [1217], il [Shunjō] désigna les deux moines Shizai et Kōmyō pour les envoyer ${ }^{71}$, en leur donnant le Commentaire $d u$ Vinaya en Quatre Sections - composé par le maître en discipline Fali ${ }^{72}$ —, avec de l'argent et plusieurs dizaines d'objets. Après que les deux moines furent partis du port de Hakata, ils disparurent avec leurs biens ${ }^{73}$. L'on ne sait s'ils sont morts ou vivants ${ }^{74}$. Seraient-ce les lames hurlantes à l'écume blanche déferlant sur le navire

67. Dugu Yuncui 㬎㨁零料: on ne connaît pas autrement ce personnage.

68. Ryōyū 是鿆 (1159-1231), Ankaku '货盁 de son nom courant (gō). Il s'agit d'un frère puiné d'Eisai. En 1187, il fait le vœu de copier le canon bouddhique, puis il se rend en Chine plus d'une dizaine d'années, et revient au Japon après avoir mémorisé, rapporte-t-on, la totalité du canon. Il réside au

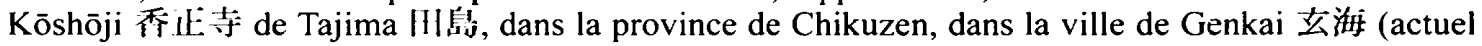
département de Fukuoka). Il réalise son vœu de copier le canon bouddhique au début de l'ère Shōgan (1207-1210). Biographie dans le Honchō kōsōden, XIII, DNBZ, vol. CII, p. 110. D’après Fujita 1972 (p. 293), Ryōyū semble avoir séjourné au Sennyūji auprès de Shunjō.

69. $T$ ajoute: «pour la donner au maître de la Loi [Shunjō] ».

70. Jian Hongchu 錢弘俶 (929-988) des Cinq Royaumes, roi de Wu et Yue, issu de Rinan dans le Kangzhou. Converti au bouddhisme, sur le modèle de l'empereur Aśoka, il fit en 955 édifier 84000 stūpa en fer dans lesquels il fit mettre une "dhāran̄ī, de l'esprit du sceau de la boîte aux trésors " (hōkyōin shinju 空䈐印心呪). Il mourut en 988. Voir Biographie des moines éminents des Song [Song Gaosengzhuan 柂高僧傳], 239; Recueil de la transmission de la lampe de l'ère Jingde [Jingde chuandenglu 崇徳傳燈録], XIX, XXI, XXV, XXVI; Biographies précieuses des moines de la forêt de Dhyāna [Chanlin baoxun 燀林得訓], VII; Biographies généalogiques des Buddha et des patriarches [Fozutongji 佛祖統記], X, XXIII, XLIII; Abrégé de l'imitation des anciens bouddhistes [Shishi jigulu 釋氏榄古略], III ; Histoire des Cinq Royaumes [Wudai shi 五代史], LXVII; Histoire des Song [Song shi 杂史], CCCCLXXX; Histoire abrégée du Japon [Fusō ryakki 扶桑略記], XXVI; Recueil complet des trésors nationaux japonais [Nihon kokuhō zenshū H本國算全集], Tōkyō, ministère de l'Éducation nationale (Monbushō), 1929-1938.

\section{1. $T$ rajoute: «en Chine ».}

72. Fali 法碝 (569-635) est le fondateur de la branche Xiangbu 相部宗 de l'école disciplinaire rivale de celle de Daoxuan 道宣. C'est son courant qui fut introduit au Japon à l'époque de Nara, en 734, par Dōsen (Daoxuan) 道點 (702-760), un élève de Dingbin 定頡 (730?-736?), grâce aux deux moines Eiei (Yōei) 榮颚 (?-749) et Fushō 炎照 (?-758), et dont Ganjin avait également hérité en partie : c'est à ce dernier que Gyõnen, dans son Historique de la transmission du bouddhisme dans les Trois Pays

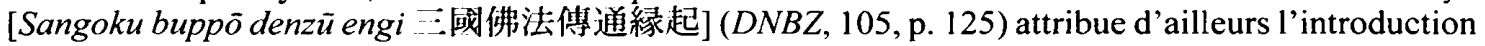
du commentaire en question. Fali a composé en 626 un Commentaire au Vinaya en Quatre Sections en vingt volumes $(Z Z, 1,65,3-5$, p. 179-488). C'est l'un des trois grands commentaires chinois de ce vinaya, avec celui de Huisu 臌来 (634-707), de l'école du stūpa de l'Est 来塔, ‘s, et celui de Daoxuan.

73. $T$ ajoute: « et l'on n'eut plus jamais aucune nouvelle d'eux ».

74. $T$ ajoute l'exclamation «Ah ! » 
qui les ont précipités dans les bas-fonds des dragons ${ }^{75}$ ? $\mathrm{Ou}^{76}$ serait-ce que les tornades glauques auraient gonflé les voiles à en faire échouer le vaisseau sur l'Île aux Démons $^{77}$ ?

Le $8^{\mathrm{C}}$ mois de la même année [1217], en réponse à la demande du gouverneur de la province de Yamato, Nakahara no Nobufusa ${ }^{78}$, inspecteur du cinquième rang en disponibilité, il conduisit soixante-sept adeptes et disciples ${ }^{79}$ dans la province de Buzen, dans le Chinzei ${ }^{80}$. Nobufusa y entra en religion ${ }^{81}$ et reçut les Règles sous le maître de la Loi [Shunjō], avec le nom de religion de Dōken. Lui et sa femme s'adonnèrent à une septaine ${ }^{82}$ de culture à rebours des racines de bien ${ }^{83}$. Une fois la cérémonie finie, le maître de la Loi s'en retourna à la capitale.

L'été de l'année suivante [1218], Dōken monta à la capitale et fit don au maître de la Loi du Sen.yūji. Ce monastère ${ }^{84}$ avait été édifié par le ministre de gauche Yamamoto Otsugu [山本緒嗣] pour le saint homme Shinshū

75. $T$ : « qui les a engloutis dans l'océan aux dragons ».

76. $T$ ne porte pas « Ou».

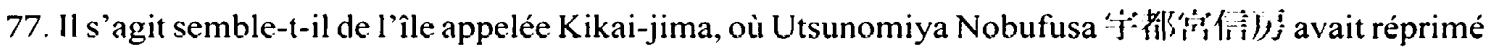
les Heike. Associée à cet épisode des guerres civiles, l'auteur de la biographie y voit-il une vengeance posthume des esprits courroucés des Heike sur des partisans de Nobufusa? Le nom de l'île est transcrit

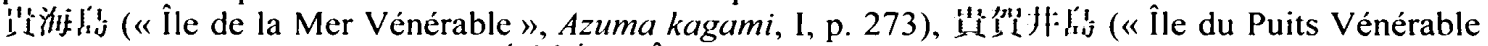

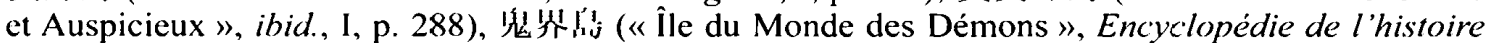

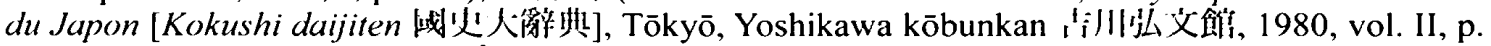
132). Il semble que la graphie 'l' ("vénérable»), employée pour la syllabe $k i$, soit un euphémisme pour 䰠 (《 démons »).

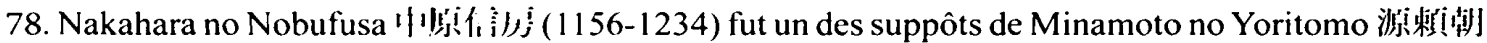
(1147-1199) dans sa lutte contre les Heike. Le Sonpi bunmyaku py branches nobles et basses) le donne pour un fils de Fujiwara no Munefusa qui aurait pris le nom de Nakahara, mais selon l'Azuma kagami (I, p. 202), il serait en réalité le petit-fils de ce dernier. Le nom d'Utsunomiya qu'on lui avait donné pourrait remonter à l'époque de son ancêtre Munemaru, qui s'était établi dans cette région de Shimotsuke. Munemaru était gouverneur du Yamato et membre de la Chancellerie privée de l'empereur (kurōdo shoshu). En 1185, il reçut le district de Sakai (anciennement Kii), du Denpōji dans la province de Buzen, ainsi que la fonction d'administrateur (goshoku) de la même province. L'Azuma kagami le mentionne entre 1181 et 1195 , où il se signale en réprimant les partisans des Heike sur l'île de Kikai-jima, à la frontière de la Corée (1187); cette action lui valut d'être gratifié du domaine de Yoshizume 着程往: situé à ōmi. En 1192, il recevait le domaine d'Igata, ainsi que la charge de jitō sur 200 chō à Hyūga (Tooin). Après des séjours à Kamakura et Kyōto, il s'établit à Buzen à la fin de sa vie. Sa descendance devait rester dans le district de Kii et y prendre le nom de Sakai. Un de ses cousins, Yoritsuna 粘維 (1172-1259), poète ami de Teika, épousa une fille de Hōjō Tokimasa 北條将政 (1138-1215), sœur de Hōjō Masako 北條政 S (1157-1225) [Sonpi bunmyaku, IV, p. 22], avant de se faire moine disciple de Hōnen et appui de Shōkū tiv' (1177-1247), lui-même fils de Minamoto no Michichika 源通䅐 (1149-1202) [Sonpi bunmyaku, III, p. 512]. DNS, IV-15.

79. $T$ ne porte pas « disciples ».

80. $T$ ne porte pas « dans le Chinzei ».

81. $T:$ : prit la tonsure ».

82. «Une septaine" : manque dans $T$.

83. Prier de son vivant pour son salut posthume, en recevant les Règles, un nom religieux et en faisant graver au vermillon son nom sur un stūpa. On considérait que cette «pratique à rebours » assurait plus de mérites que de confier à d'autres le soin de prier après sa mort.

84. $T$ ajoute: « Si l'on interroge le passé, on saura que ce monastère... » 
[神修上: 人], la $2^{\mathrm{e}}$ année de Saikō [855]. Il avait tout d'abord été appelé Hōrin[ji] [法輪[钓] (《Monastère de la Roue de la Loi »)], puis fut rebaptisé Sen.yū[ji] [仙遊[洔] (《Monastère oủ Randonnent les Immortels »)]. Maintenant, on a changé son nom en Sen.yū[ji] [泉涌[寺] (《Monastère du Jaillissement de la Fontaine »)].

Le $3^{\mathrm{e}}$ mois printanier de la $1^{\text {re }}$ année de Jōkyū [1219], il y eut délibération à la Cour sur le projet de construire ${ }^{85}$ une île [artificielle] pour accueillir les voyageurs dans la baie d'Uozumiura, dans la province de Harima, mais il n'y eut personne qui voulût en entreprendre l'édification. Tous, se réjouissant des facultés du maître de la Loi, le proposèrent pour cette tâche ${ }^{86}$. C'est pourquoi le dignitaire inspecteur des provinces du Nord, l'intendant Fujiwara no Michichika, fit émettre un décret de la part de l'empereur [retiré Gotoba] ${ }^{87}$. Mais le maître de la Loi refusa vigoureusement et ne voulut pas s'y soumettre. Il fut loué ${ }^{88}$ pour sa pureté et son absence d'ostentation dans sa pratique de la Voie.

Le $2^{\mathrm{e}}$ mois de la $2^{\mathrm{e}}$ année de Jōkyū [1220], il présenta à l'empereur retiré Gotoba deux registres de quêtes d'aumône du Sennyūji ainsi qu'un règlement des cérémonies pour les pavillons monastiques ${ }^{89}$; l'exposé des intentions de son vœu sortait de l'ordinaire. Le texte de dragon et l'écriture sigillaire d'oiseau qu'il avait calligraphiés de sa propre main frappèrent les oreilles et les yeux des dignitaires de la Cour réunis, si bien que, les ayant vus, l'empereur donna son assentiment et lui fit remettre une offrande de quinze mille pièces de soie par le dignitaire inspecteur des provinces du Nord, l'intendant Fujiwara no Michichika. Le prince entré en religion Gotakakura donna lui aussi son assentiment et lui fit remettre une offrande de quinze mille pièces de soie par le dignitaire intendant, l'auditeur Minamoto no Masakiyo ${ }^{90}$.

85. $T$ ajoute: «nouvellement ».

86. $T$ : «Quand il fallut choisir quelqu'un pour l'édifier, des gens proposèrent lc nom du maitre de la Loi. »

87. Fujiwara no Michichika 滕㹸光視 (1176-1221) est l'un des grands personnages de son époque. Proche de l'empereur retiré Gotoba et poète renommé, il connut un sort tragique, souligné par les récits de l'époque (Azuma kagami, Biographie de Myōe) : capturé au moment des troubles de l'ère Jōkyū, au cours desquels on avait tenté de renverser le bakufu sous la bannière de Gotoba en mettant à profit l'assassinat du troisième shōgun, Minamoto no Sanetomo, Michichika fut exécuté ; juste avant de mourir, il composa un poème émouvant devant la fragilité des affaires humaines. À la suite de cette

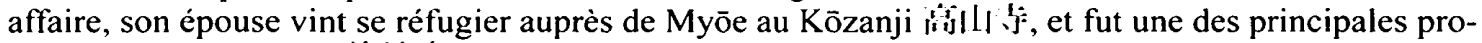
tectrices du Zenmyōji 善妙行, le monastère pour moniales édifié par Myōe à proximité du Kōzanji. Myōe avait échangé des poèmes avec Michichika. Son intervention, ici, témoigne des liens étroits qui existaient entre Shunjō et la cour impériale. Voir le Sonpi bunmyaku, II, p. 104.

88. T ajoute: « aussi bien à la capitale que dans les provinces ».

89. Les deux textes sont conservés et reproduits dans Ishida 1972 (éd.).

90. On ignore les dates de Minamoto no Masakiyo 源雅清. Il était auditeur du troisième rang, et des poèmes composés par lui figurent dans le Recueil compilé sur ordre impérial [Shinchokusen wakashü

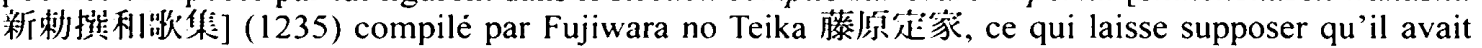
des liens avec le bakufu et n'avait pas pris le parti de Gotoba au moment des guerres civiles de Jōkyū. Masakiyo était frère cadet de Masachika 雅親 (1180-1249) et fils de Michisuke [通資] (?-1205) et d'une fille de Fujiwara no Nagasuke [滕原昼洲輔] (? - ?), ce qui en fait un neveu du fameux Minamoto no Michichika et un cousin du fils de ce dernier, Michitomo 通 ! que de Michikata, mentionné plus loin. Voir le Sonpi bunmyaku, III, p. 498. 
Le $3^{\mathrm{e}}$ mois du printemps de la $3^{\mathrm{e}}$ année de Jōō [1224], il demanda que le Sen.yūji fût désigné temple de vœu impérial.

La même année, le premier [jour] du $7^{\mathrm{c}}$ mois ${ }^{91}$, le second conseiller surnuméraire, le dignitaire Minamoto no Michikata ${ }^{92}$, reçut l'ordre impérial d'émettre le décret.

L'hiver ${ }^{93}$ de la même année, le $10^{\mathrm{e}}$ mois, il se rendit dans le Kantō à l'invitation de l'inspecteur de $\mathrm{Bi}\left[\right.$ zen], Taira no Ietsura ${ }^{94}$. Aux étapes où il faisait halte, le vent faisait coucher les herbes, les eaux débordaient sur les ponts, les dames galantes en oubliaient de se maquiller et recevaient les Règles, les pêcheurs jetaient filets et perches pour écouter prêcher la Loi ${ }^{95}$. Il arriva enfin au pavillon Miura d'Ietsura. Il y inaugura un monastère ${ }^{96}$; à la suite de quoi, il se rendit à Kamakura. Là, la moniale de Dhyāna du deuxième rang — Nyojitsu, de son nom taboué ${ }^{97}$ ainsi que le contrôleur de Musashi, le dignitaire Hōjō Yasutoki ${ }^{98}$, reçurent ${ }^{99}$ de lui les règles de bodhisattva. Il resta en tout et pour tout une semaine à Kamakura,

91. $T: « d u$ mois intercalaire ».

92. Minamoto no Michikata 源通方 (1189-1238), fils de Minamoto no Michichika et de Fujiwara no Hanshi 滕原範 了' (?-1200), [Sunpi bunmyaku, II, p. 478], puîné de Michitomo. Il élail grand conseiller du deuxième rang principal. Voir le Sonpi bunmyaku, III, p. 512.

93. “L'hiver » : manquant dans $T$.

94. Issu du lignage Kanmu Taira, Taira Ietsura 我連 était Miura - du nom du domaine qu'ils avaient à Sagami depuis le $X^{\mathbb{}}$ siècle — par son grand-père, le célèbre homme lige de Yoritomo, Miura

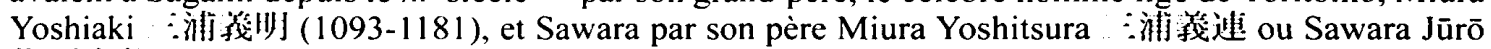
倍源恻 (?-?). Il figure dans l'Azuma kagami, entre les dates de 1228 et de 1243, sous le nom de Miura Saburō Saemon no jo [ "fonctionnaire de troisième classe de la garde des portes de gauche »]

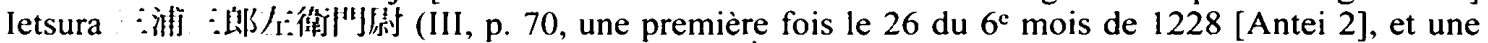
dernière fois le $1^{\mathrm{er}} \mathrm{du} \mathrm{l}^{\mathrm{er}}$ mois de 1237 [Katei 3]). À partir du $17 \mathrm{du} 2^{\mathrm{e}}$ mois de 1238 jusqu'au $17 \mathrm{du}$ $7^{\mathrm{c}}$ mois de 1243 , il est mentionné en qualité d'ancien gouverneur de Bizen. Le $24 \mathrm{du} 12^{\mathrm{c}}$ mois de 1236 [Katei 1], il est nommé pour officier à une cérémonie à Kumano, au Pavillon principal, tandis qu'un cousin de Myōe, Yuasa Munenari 晹浅宗業 (1196-1270- ?), entré en religion sous le nom de Chigen 智眼 et auteur présumé du Jikkinshō (ibid., III, p. 144), officie à Nachi, et que le moine Gyōyū 行甬 (1163-1241) exécute le rituel de l'oblation ignée. Le $10 \mathrm{du} 12^{\mathrm{e}}$ mois de 1227 (Karoku 2), Fujiwara no Kagenori 藤原罻倫 (?-1276), homme lige du shōgun Sanetomo, entré en religion à la mort de ce dernier sous le nom de Ganshō 願性: sous Gyōyū 行勇 au Kōyasan 高野|l, inaugurait le monastère Saihōji à Yura, dans la province de Kii, pour le salut posthume de Sanetomo et de Hōjō Masako, après avoir demandé à Myōe de choisir le nom du temple et à Dōgen de le calligraphier (Chronologie des actes authentiques du maître national Hattō Enmyō (Shinji Kakushin), fondateur du Washigamine [Wash-

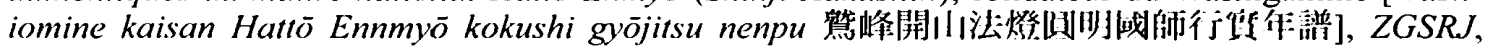
vol. IX, p. 348-349). Sur les liens qui pouvaient exister entre Myōe, Gyōyū et Shunjō, voir Girard 1990, p. XXXVIII-XXXIX, n. 23 et 536. DNS, IV-7, le 17 du $5^{\mathrm{c}}$ mois de Kennin 3. Son nom n'est pas mentionné dans le Sonpi bunmyaku, IV, p. 14.

95. Les femmes qui vendaient leurs charmes et les pêcheurs appartiennent à une même catégorie de parias mis au ban de la société. Nichiren, fils de pêcheur, se considérait lui-même comme un canḍala. Shunjō, tout comme Dōgen d'ailleurs, n'ont-ils pas eu conscience d'être nés de courtisanes qui s'étaient unies à un père à un tel point absent que son identification était problématique ?

96. $T$ ajoute : « nouvellement édifié ».

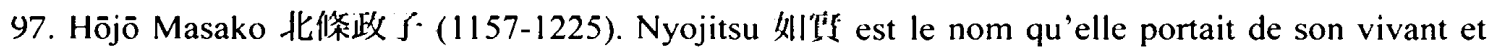
qu'on ne prononça plus après sa mort.

98. Hōjō Yasutoki 北條泰宜 (1183-1242) était le régent du bakufu.

99. $T$ ajoute: « en même temps » (ou « ensemble »). 
durant laquelle il prodigua les enseignements des règles disciplinaires et fit l'éloge des sütra prêchés par le Buddha. Moines et profanes venaient le révérer jour et nuit sans arrêt ${ }^{100}$.

Le 20 du $10^{\mathrm{c}}$ mois de 1225 [Karoku 1], il entreprit d'édifier le Pavillon de prédication à plusieurs étages [du Sen.yūji].

À la fin du printemps de l'année suivante [1226], ce pavillon fut inauguré dans toute sa magnificence. On y tint alors la retraite d'été de neuf décades ${ }^{101}$. Il monta dans la chaire de prédication pour y expliquer les deux méthodes d'exposition de la Loi des écoles doctrinales et disciplinaires ${ }^{102}$. Ce monastère était le seul à prendre pour modèle les usages en règle chez les Grands Song. Parmi les moines et les laïcs de tout le pays, depuis l'empereur et les dignitaires jusqu'[au peuple], il n'était personne qui ne révérât la discipline et la vertu du maître de la Loi. À l'époque, l'empereur retiré Gotoba reçut de lui les règles de bodhisattva dans le pavillon Kayōin. Toutes les femmes de la cour ainsi que les ministres et les dignitaires furent unanimes pour révérer en lui un modèle de discipline et pour ceindre le collier de la discipline. L'empereur retiré Juntoku ${ }^{103}$ reçut lui aussi les règles de bodhisattva en formant le serment solennel de rencontrer la Loi au cours de ses existences successives. Le prince entré en religion Gotakakura ${ }^{104}$ reçut à son tour les règles de bodhisattva dans le pavillon du Jimyōin. La princesse Higashi Ichijōin ${ }^{105}$ reçut les Règles après avoir attaché sa ceinture. C'est elle qui donna naissance avec bonheur à l'empereur qui fut déchu lors des troubles de Jōkyū ${ }^{106}$. L'épouse du grand dignitaire du Dhyāna du Hosshōji ${ }^{107}$, la grande dame de service assimilée à la troisième impératrice ${ }^{108}$,

100. $T$ ajoute: «Une fois qu'il eut accompli son service religieux, il s’en retourna à la capitale. »

101. Eisai passe pour avoir réintroduit au Japon l'usage des retraites d'hiver et d'été, dont il déplorait la désaffection au Japon (Kōzen gokokuron, NST, 16, p. 83).

102. Les écoles doctrinales (celles de Nara et de Heian), et l'école disciplinaire, auxquelles s'ajoutent celles du Dhyāna, selon Eisai par exemple. $T$ : « Il y avait force mouvement à l'intérieur du pavillon et le siège de prédication montait et descendait. "

103. Né en 1197, mort en 1242.

104. Shutei 守战.

105. T ajoute: «Risshi ». Risshi 衣子 (1192-1247), fille de Fujiwara no Yoshitsune 滕原䔐經 (11691206) et d'une fille de Fujiwara no Yoshiyasu 藤原能保 (1147-1198) [Sonpi bunmyaku, I, p. 259-261], eut elle-même pour sœurs cadettes les épouses de Minamoto no Michitomo et de Saionji no Kintsune. Elle fut l'épouse de l'empereur retiré Juntokuin et eut de son union avec lui l'empereur retiré Chūkyōin 仲茶院 $(1218-1234)$.

106. C'est-à-dire Chūkyōin.

107. Fujiwara no Michiie (1183-1268).

108. Rinshi 綸子 (ou f倫子), l'une des filles de Saionji no Kintsune, et épouse du premier rang secondaire et troisième altesse impériale [Sonpi Bunmyaku, I, p. 89]. Elle est mère de Fujiwara no Norizane (1208-1235), un des patrons de Dōgen. Le texte semble suggérer que Shunjō lui donna les règles disciplinaires en 1225, alors qu'elle était enceinte de Yoritsune. Mais celui-ci naquit le 16 du $1^{\text {er }}$ mois de 1218 (Kenpō 6), sous une bonne étoile : une année du Tigre, un mois du Tigre el pendant l'heure du Tigre. Si le récit est juste, faut-il simplement penser qu'il énumère, sans grande préoccupation chronologique, une liste de personnages ordonnés par Shunjō? Sinon, on pourrait croire qu'il a 
reçut les règles disciplinaires au cours de sa grossesse. Après une semaine, Rinshi acccoucha sans difficulté du généralissime pacificateur des barbares ${ }^{109}$. On peut ajouter à ces personnages l'adepte du Dhyāna ministre des affaires suprêmes de la première avenue ${ }^{110}$, l'ancien tiers ministre Koga ${ }^{111}$, l'ancien ministre de droite Reizei ${ }^{112}$, ou encore le dignitaire Mitsuchika, inspecteur des provinces septentrionales ${ }^{113}$, qui prêtèrent un serment religieux et donnèrent constamment leur appui à la Loi.

En outre, Jōkei, le célèbre maître versé dans les doctrines gnoséologiques ${ }^{114}$, déplorant constamment que la bannière de la Discipline fût renversée, voulait

pris en exemple le plus célèbre des fils de Michiie, devenu le quatrième shōgun à la mort de Sanetomo, grâce à l'intercession de Rinshi, elle-même fille d'une nièce de Yoritomo, qui prit le parti du bakufu dès les troubles de l'ère Jōky'ū. Comme il semble qu'on se trouve à une date trop précoce pour qu'il puisse s'agir de Fujiwara no Sanetsune 藤原實經 (1223-1284), on pourrait également penser à un des

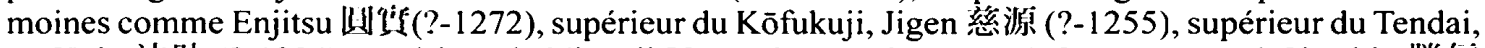
ou Hōjo 法助 (?-1284), supérieur du Ninnaji [Sonpi bunmyaku, I, p. 101] ; ou encore à Shōshin 勝信 (1225-1287), supérieur du Tōdaiji, qui naquit pendant l'année ici mentionnée [ibid., p. 102]. Le récit construit-il l'histoire afin de se concilier les grâces du bakufu tout en ménageant la maison impériale ?

109. $T$ ajoute: « Yoritsune ». Voir Sonpi bunmyaku, I, p. 101.

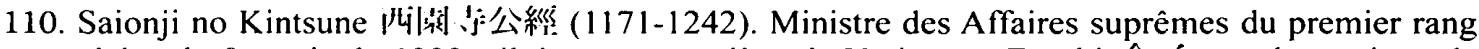
secondaire (le $8^{\mathrm{c}}$ mois de 1222 ), il épousa une nièce de Yoritomo, Zenshi $\left.\hat{1}\right\}^{\circ}$, par le mariage de Fujiwara no Yoshiyasu avec une tante maternelle de Yoritomo. Il fonda le monastère du Saionji en

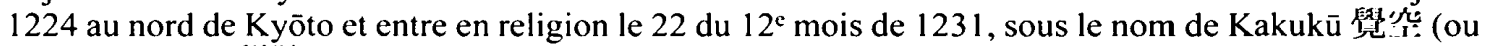
plutôt Kakushō 留腾), [Sonpi bunmyaku, I, p. 150]. Il se rapprocha du Bakufu par le mariage de sa fille Rinshi avec le quatrième shōgun, Yoritsune, et durant les troubles de Jōkyū, où la cour impériale tenta de reprendre le pouvoir au gouvernement militaire, il contribua au succès du bakufu en éventant les nouvelles sur la situation à Kyōto. C'est lui qui semble avoir placé Gohorikawa sur le trône impérial

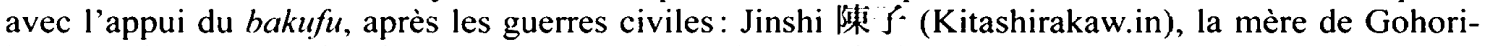
kawa, était une sœur de Kintsune (DNS, V-18, 29 du $8^{\mathrm{e}}$ mois de Kangen 2 [1244]).

111. D'après les dates, il s'agirait non pas de Minamoto no Michichika, qui est bien connu sous ce titre, mais de son quatrième fils, Minamoto no Sadamichi 源定通 (1188-1247), qu'il eut de Hanshi, lequel fut tiers ministre du deuxième rang principal, et poète du Shinchokusen wakashū. Voir le Sonpi bunmyaku, III, p. 509.

112. Minamoto no Michimitsu 源通光 (1185-1248), troisième fils de Minamoto no Michichika et de Hanshi, frère puiné de Michitomo et aîné de Michikata [Sonpi bunmyaku, III, p. 503]. Il n'existe pas sous ce nom dans le Sonpi bunmyaku, mais l'Azuma kagami l'appelle "grand conseiller Michimitsu " (le 6 du $3^{\mathrm{e}}$ mois de 1213 [Kenbo 1]), "garde de droite » (5 du $6^{\mathrm{e}}$ mois de 1218 [Kenbo 6]), et « ministre des Affaires suprêmes de Reizei» (les 5 et 14 du $6^{\mathrm{C}}$ mois de 1247 [Hōji 1]) [II, p. 382 et 386]. Il devint ministre des Affaires suprêmes le 24 du $12^{\mathrm{e}}$ mois de 1243 (Kangen 4), premier rang secondaire (Kugyōbunin, II, p. 131). Auparavant, il avait été désigné ancien tiers ministre du 3 du $7^{\circ}$ mois de 1221 (Jōkyū 3), [ibid., p. 38] (1245 [Kangen 3], p. 129), charge qu'il occupait depuis le 4 du 3e mois de 1212 (Kenbo 7). Il devint général de la garde de droite le 28 du $1^{\text {er }}$ mois de 1217 (Kenbo 5), [ibid., p. 21]. Il entra au Conseil comme hisangi le 21 du $4^{*}$ mois de 1201 (Kennin 1), [ibid., IV, p. 548-549], fut fait hisangi uchüshū à 17 ans en 1203 [ibid., p. 553], devint second conseiller le 12 du $4^{\mathrm{c}}$ mois de 1204 [Kennin, 4], [ibid., IV, p. 556] et grand conseiller surnuméraire le 10 du $2^{\mathrm{c}}$ mois de 1207 [Ken.ei 2], [ibid., p. 565].

113. Il devint second conseiller en cumulant la charge d'inspecteur des régions septentrionales en 1216 [Kugyō bunin, II, p. 18]. Sa carrière est détaillée jusqu'en 1208 [ibid., I, p. 568-569].

114. Jōkei 貞庡 (1155-1213): ce moine de l'école gnoséologique est également connu pour avoir voulu restaurer le code disciplinaire, tentative dont la biographie de Shunjō se fait l'écho. Il était fils de Fujiwara no Sadanori 滕原貞慧 (actif en 1159) et petit-fils de Fujiwara no Michinori 滕原通憲 (11061159). Il passait pour avoir obtenu des pouvoirs thaumaturgiques grâce à sa concentration mentale. Voir le Sonpi bunmyaku, II, p. 488. 
s'efforcer de la restaurer. Soit il rédigeait des lettres pour poser les problèmes, soit il dépêchait des disciples afin d'élucider ceux-ci ${ }^{115}$. Or, comme il lui avait manqué la transmission venant d'un maître, en vérité, nombreux étaient les points de doctrine auxquels il n'avait pas accès ${ }^{116}$. Comme il arriva par bonheur que le maître de la Loi était de retour de Chine, il lui fit part des doutes qu'il entretenait depuis des années et sur-le-champ le maître de la Loi lui répondit pleinement, selon la bonne tradition. La glace de ses doutes fondit immédiatement. Les brumes de son ignorance se dissipèrent en un instant.

Ce qu'a professé Jōkei se limitait au Traité sur la pratique du Vinaya en Quatre Sections, et il n'avait encore jamais consulté les Commentaires sur les règles disciplinaires ni le Commentaire sur les actes ni non plus le Traité sur le sens du $V_{\text {Vinaya }}{ }^{117}$. À combien plus forte raison [en ignorait-il] le sens ! Grâce à leur transmission par le maître de la Loi, ces textes commencèrent à circuler.

De manière générale, si les règles en vigueur à cette époque ont été pratiquées, c'est en grande partie à l'influence du maître de la Loi qu'on le doit. Il en fut de même pour l'observance du jeûne ${ }^{118}$ qui, bien que pratiquée par les sages du passé, ne suivait plus aucune règle stricte ${ }^{119}$ : c'est grâce aux explications du maître de la Loi qu'on put enfin l'accomplir selon les règles. De même, la possession de vêtements et de bols à aumône fleurit en notre époque, jusqu'à un point auparavant inconnu. C'est grâce au maître de la Loi qu'une tradition [exacte] a été transmise [sur cette question]. On peut dire qu'il est celui qui a renoué les rênes subtiles, qui étaient rompues, et qu'il a rétabli la grande enseigne qui avait été renversée.

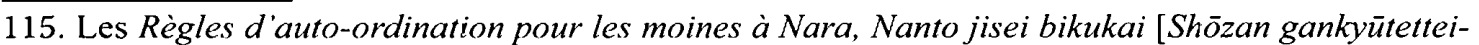
shō] signalent que Jōkei, dès le retour de Shunjō de Chine, avait envoyé son disciple Kainyo Chisokubō chez Shunjō afin de l'interroger sur ses doutes concernant le Shibunritsu gyōjishō de Daoxuan, et que Shunjō lui donna le commentaire de cet ouvrage rédigé par Yuanzhao, qu'il avait ramené du Continent (le Gyōjishō shijiki), ce qui permit à Jōkei de dissiper tous ses doutes. (NDZ, XXXV, cité par Tokuda Myōhon, « Le maître de discipline Shunjō et le code disciplinaire de Nara », dans Ishida 1972 (éd.), p. $66-82$, voir p. 69 et n. 13).

116. $T$ ajoute ici la phrase : «En effet, sa seule référence se limitait au Traité sur la pratique du Vinaya en Quatre Sections, et il n'avait encore jamais consulté les Commentaires sur les règles disciplinaires ni le Commentaire sur les actes ni non plus le Traité sur le sens du Vinaya. »

117. Titre complet : Traité sélecrif sur les pratiques du Vinaya en Quatre Sections [des Dharmaguptaka]. Sifenlu shanfan buque xingshichao 四分律刪繋補閶行事鈔, composé par Daoxuan (595-667) en 626 ( $\left.T, \mathrm{XL}, \mathrm{n}^{\circ} 1804 ; Z Z, \mathbf{I}, 69,1-70,1, \mathrm{p} .73-498\right)$. Le Commentaire sur les règles disciplinaires est le Commentaire fondamental sur les règles disciplinaires des moines selon le Vinaya en Quatre Sections, Sifenlu biqiou jiebenshu 四分律比斥戒本疏, rédigé par Dingpin (713-741), [T, XL, n $1807 ; Z Z, I$, 62, 1, p. 1-31]. Le Commentaire sur les actes est le commentaire sélectif circonstancié sur les actes selon le Vinaya en Quatre Sections, Sibenlu shanbu suiqi jiemo shu 四分律随機羯磨疏, composé par Daoxuan en 648 (ZZ, 1, 64, 3-5, p. 260-510). Le Traité sur le sens du Vinaya est le Traité collectant le sens du Vinaya selon le Vinaya en Quatre Sections, Sifenlu shipini yichao 四分律拾琰尼義鈔, composé par Daoxuan en 627 (ZZ, I, 71, 1, p. 30-73).

\section{Jisai 持䮺.}

119. Telle a été la critique d'Eisai à l'égard des pratiques dans les temples bouddhiques au Japon, et ce qui a motivé l'un de ses séjours en Chine (voir le Kōzen gokokuron, NST, 16, p. 41 et 81 [le jeûne prolongé et la diète tombés en désuétude au Japon], 83 [la pratique des deux retraites à restaurer au Japon]. 
Le maître Jishin ${ }^{120}$, supérieur du Tendai, feu le grand recteur monacal Bonshitsu ${ }^{121}$, ainsi que d'autres personnages, prirent chaleureusement refuge en lui et lui posaient des questions incessantes. Ils le révéraient tout particulièrement et cherchaient à qui mieux mieux à en obtenir des mérites ${ }^{122}$ Son Excellence du Dhyāna du Hosshōji [Fujiwara no Michiie] ainsi que le ministre ${ }^{123}$ du Tokudaiji $^{124}$ [Kintsugu]. Ce dernier était descendant de Hitoyoshi ${ }^{125}$, petit-fils du ministre de droite Daisuigomon ${ }^{126}$, et fils du ministre de gauche Gotokudaiji ${ }^{127}$.

La vigueur insigne de Shunjō tranchait sur celle du commun et sa stature gigantesque dépassait la norme. Prêchant la voie de l'antiquité, il répondait aux invitations clairvoyantes ${ }^{128}$. À l'égard du gouvernement actuel, il dispensait sa sagesse. Il était un père et une mère pour le peuple et apportait son soutien à l'empereur. S'il priait, ce n'était pas pour thésauriser; toutes ses richesses consistaient en de nombreux textes ${ }^{129}$. Il a fait la synthèse des écrits des cent philosophes des neuf courants et

120. Jien 慈圆 (1155-1222). Fils du régent et grand chancelier Fujiwara no Tadamichi 藤原忠通 (1097-1164), il était frère utérin de Kujō Kanezane 九條兼䆩 (1149-1207)). Il se fit moine en 1167 [Nin.an 2] au Hieizan, avec le prince entré en religion Kakukai, au pavillon Shirakawa du Shōren.in du Stūpa oriental. Il prit son nom de Jien en 1181 [Yōwa 1]. Il devint moine protecteur (gojisō 護持僧) de l'empereur Gotoba en 1192, année où il devint supérieur du Tendai ; il le redeviendra quatre fois, après des démissions imposées par la situation politique. Il fut grand recteur monacal en 1203 [Kennin 3]. Après la mort de Kanezane, il devint conseiller (ushiromi 後身) de la branche Kujō des Fujiwara et s'efforça de jouer un rôle conciliateur entre les guerriers et la noblesse de Kyōto. Il écrivit à cette fin son histoire raisonnée du Japon, le Gukanshō, qui essayait de fonder en raison (dōri 道理) une telle concorde, mais les guerres civiles de Jōkyū [1221] ayant définitivement rompu cette dernière, il se replia dans une retraite solitaire.

121. Personnage non identifié. Parmi les supérieurs du Tendai ayant vécu à l'époque de Jien ou antérieurement à lui, on peut mentionner Kōen 公圆 (mort en 1235), [Sonpi bunmyaku, I, p. 144], Enki 则哲 (mort en 1232), un fils de Konoe Motomichi 近衛基通 (1140-1233)) qui fut grand recteur monacal [Sonpi bunmyaku, I, p. 69], Shōen 承猡 (1180-1236), un fils de Matsudono Motofusa 松怴基 bj (1147-1230) qui fut grand recteur monacal [Sonpi bunmyaku, I, p. 83], Shinshō 黄性: (mort en 1230) et Jitsuzen 战全 (1141-1221), fils de Takudaiji Kinyoshi 徳大寺公能 (1114-1161). Voir le Sonpi bunmyaku, I, p. 184.

122. Cette phrase manque dans $T$.

123. $T$ ajoute : « de gauche».

124. $T$ place ici le membre de phrase : «le révéraient tout particulièrement ».

125. Hitoyoshi 1 . 戥 : nom posthume du ministre des Affaires suprêmes Fujiwara Kintoshi 1公李 (9571029), fondateur de la lignée. Voir le Sonpi bunmyaku, I, p.119.

126. Il s'agit de Tokudaiji Kinyoshi I公能 (1115-1161). Voir le Sonpi bunmyaku, I, p. 177 et Joüon des Longrais, 1965, p. 21-24.

127. Gotokudaiji Sanesada 1後徳大洔斯定 (1139-1191) [Sonpi bunmyaku, I, p. 179] était frère utérin de Tashi 多\}, celle qui épousa deux empereurs [Joüon des Longrais, 1965, p. 23-25]. Il était un proche de Minamoto no Yoritomo. Il entra en religion sous le nom de Nyoen 加保 en 1191. Il a laissé un journal, le Jittei kōki 實定公記, dans lequel il décrit la décadence de la cour impériale. Excellent poète, on a de lui un recueil de trois cent quatre-vingts pièces, le Rinkashü 林下集 ; son nom apparaît dans le Heike monogatari.

128. Manque dans $T$ : «Disposant de la voie de l'antiquité, il faisait appel à des gens clairvoyants. "

129. $T$ : « Il ne s'enorgueillissait de beaucoup de biens et faisait des lettres et des armes sa richesse. » 
était versé dans les textes des cinq prosternations aux six moments de la journée ${ }^{130}$. Il était fidèle à la rectitude sans suivre servilement par familiarité. En outre, il affectionnait les certificats d'airain du palais du dragon ${ }^{131}$ et se jouait perpétuellement des principes précieux du Pic des Vautours ${ }^{132}$. Il ne regardait pas à la gloriole des couronnes et affectionnait dans son cœur la doctrine de Śākyamuni. Tel était son zèle ! Il était également connu à la cour et en province. Et, là-dessus, après que le maître de la Loi se fut rendu à la capitale, lorsque le ministre de gauche [Kintsugu ?] eut une entrevue avec lui, il l'implora instamment en lui déclarant: « À chaque fois que j'accumule des doutes, je me trouve en difficulté. N'ayant pas encore rencontré de maître éclairé, je soupire après vous comme un homme affamé après sa pitance $^{133}$. J'ai par bonheur pu rencontrer le maître de la Loi et je l'implore de ne pas s'éloigner pour faire retraite ${ }^{134}$. " Le maître de la Loi donna son assentiment en souriant ${ }^{135}$, et par la suite il ne lésina pas tout le jour et tout le mois sur les significations ${ }^{136}$ de la quintessence des lettres et sur les discussions de la dynastie des Song. Le maître de la Loi fit pour la première fois état de la quintessence profonde des Cinq Livres et des Trois Histoires ${ }^{137}$ et des significations qui n'avaient pas encore été discutées au Japon, ce dont le ministre de gauche prit connaissance, non sans en déplorer les hérésies [constatées]. Peu à peu, il pénétra dans les enseignements bouddhiques - ceux du Petit comme du Grand Véhicule —, les règles disciplinaires et les méthodes du dhyāna. Il souhaitait hautement l'interroger et, à chaque fois qu'il le faisait, [Shunjō] répondait sans laisser subsister la moindre obscurité ${ }^{138}$.

130. Cent philosophes des neuf courants : c'est-à-dire la totalité des philosophes et des courants. Sur ce genre de classification des écoles philosophiques de la Chine ancienne, voir Léon Vandermeersch, La Formation du Légisme, Recherche sur la constitution d'une philosophie politique caractéristique de la Chine ancienne, Publications de l'École française d'Extrême-Orient, Volume LVI, Paris, École française d'Extrême-Orient, 1965, notamment p. 5-7.

Les neuf courants sont ceux des écoles des Lettrés, du Taoïsme, du Yin et du Yang, du Légisme, des Dénominations correctes, des Moïstes, des Alliances, les Écoles diverses, l'École Agricole Rokujigorai 六時五澧. Le confucianisme connaît ces cinq types de cérémoniels, respectivement consacrés aux choses fastes, aux choses néfastes, aux choses militaires, à l'hospitalité et aux «événements joyeux " [mariage et imposition du bonnet viril ?], mais on ne sait rien de leur association aux six moments de la journée. Ou bien doit-on comprendre: "les salutations au Buddha Amida aux six moments de la journée [rokuji raihai 六時澧f扭]", si l'on tient compte de sa foi amidiste? En raison de ce flottement sémantique, la version de Tenpō a opté pour une autre lecture ( dans les six styles poétiques ainsi que les cinq styles en prose »), en proposant la variante graphique rokushi gotai 六就 ti骹.

131. Les textes sacrés du bouddhisme conservés au Palais des Dragons au fond de l'océan.

132. La prédication du buddha Śākyamuni. $T$ porte : «Il ajoutait foi en la parole d'airain du Palais des Dragons et se jouait des sons de jade du Pic des Vautours. »

133. Cette dernière expression, tirée du chinois, ne se trouve pas dans $T$.

134. $T:$ : de ne pas ménager son enseignement ».

135. «En souriant » manque dans $T$.

136. $T$ : « sur la sublimité ».

137. Les Cinq Livres sont: le Livre des mutations [Yijing 易經], les Annales [Shujing 卙], le Classique de la poésie [Shijing 詩經], le Livre des rites [Lijing 禮經] et les Printemps et Automnes [Chunqiu 寿秋]. Les Trois Histoires sont les Mémoires historiques [Shiji 过话] l'Histoire des Han [Hanshu 漢畫] et l'Histoire des Han postérieurs [Houhanshu 後漢畫].

138. $T$ intervertit légèrement l'ordre de tout ce passage. 
Chaque année, les $1^{\mathrm{er}}, 5^{\mathrm{e}}$ et $9^{\mathrm{e}}$ mois, durant une semaine, [Kintsugu] résidait à l'ermitage de ${ }^{139}$ Dhyāna du maître de la Loi et lui-même prenait rang parmi l'assemblée des cours. Il s'instruisait des doctrines et de la discipline, se réjouissait de la succession de ses bienfaits ${ }^{140}$ et, à chaque fois qu'il rencontrait le maître de la Loi, il concevait grandement une crainte respectueuse ${ }^{141}$. Ceci parce qu'il tenait en haute estime la Loi et respectait la Voie. Durant l'ère Jōō [1222-1224], il fit mander le maître de la Loi afin de recevoir les défenses. Une fois qu'il les eut reçues, il s'enquit des enseignements du Tendai et, acculé à maintes reprises, le maître de la Loi scruta les principes et épuisa la nature des choses sans que rien ne fût mystérieusement éloquent, à propos de la méthode d'examen mental sur le trichiliomégachiliocosme en un instant de pensée. Le ministre de gauche, en entendant pour la première fois ces doctrines, en resta stupéfait. Il laissa s'écouler des larmes à la fois de tristesse et de joie. Après un moment, il déclara ${ }^{142}$ : « Je vais mourir sans avoir entendu cette doctrine. Comment trancher ${ }^{143}$ la source originelle du cycle de la vie et de la mort ? Pourquoi ne m'avoir jusqu'à présent pas enseigné la Loi profonde et sublime ? - Le maître de la Loi, de par sa nature, ne donne pas de solution hâtive aux questions qu'on ne lui a pas posées ${ }^{144}$. Lorsque le maître de la Loi se fut retiré, le ministre de gauche l'accompagna pieds nus jusqu'au portail central. Par la suite, sa pensée de foi fut pure et sa prise de refuge sans égale. Il cultiva le bien selon sa condition et fut zélé dans ses prières. Il ne faisait que se reposer unilatéralement sur la force de l'enseignement du maître de la Loi et attacha toute sa foi à la protection du temple. En outre, comme il en avait le vœu le plus cher, [Shunjō] lui conféra le titre d'adepte laïque Yuishō ${ }^{145}$. En général, après leurs entrevues, durant plus de dix années, en dehors de leurs rencontres face à face, il lui écrivait pour l'interroger sur des points douteux. Les jours ne passaient en vain et, à l'aide des relations précédemment mentionnées, il en fit le trésor précieux de sa famille. Dans sa $53^{\mathrm{e}}$ année, au printemps, il éprouva un petit malaise et demanda au maître de la Loi d'accomplir les rituels de la fin ${ }^{146}$. [Shunjō] les lui donna par écrit - le texte en existe à part. Le ministre de gauche ${ }^{147}$ pratiqua chaque jour ces rituels et fit le vœu d'aller renaître dans la Terre pure. Il n'avait aucune autre pensée en dehors de celle-là. Lorsqu'il fit face aux derniers instants de sa vie, les gens voulurent le revêtir de la toge monastique. Comme il en était convenu de son vivant avec le maître de la Loi, il attendait maintenant ce

139. $T$ : «à côté du ».

140. «La succession de ses bienfaits » : manquant dans $T$.

141. $T$ : « une crainte sincère au plus haut point ».

142. $T$ ajoute : « il déclara au maître de la Loi... »

143. $T$ : « m’éveiller à ».

144. L'incise ne figure pas dans $T$.

145. Yishō koji 唯整艮i:

146. $T$ : « les préparatifs de la fin ».

147. $T$ : « reçut ce texte ». 
dernier. Celui-ci tardait à venir. Comme lui-même était en train d'expirer, le maître de la Loi arriva. Le ministre de gauche ouvrit instantanément les yeux et porta ses regards sur le maître de la Loi ${ }^{148}$. Celui-ci le revêtit alors de la toge monastique. [Kintsugu] s'assit en position droite, tourné vers l'Occident, fit l'añjalī et trépassa - dans la résidence de Saitōin de la troisième avenue. Son faciès était joyeux et son teint frais. Il gardait sa superbe comme de son vivant ${ }^{149}$. II avait la même souplesse qu'à l'accoutumée. À voir et à entendre cela, on concevait la pensée de l'éveil et on loua ${ }^{150}$ ce qu'il y avait là d'inouï. De nombreuses personnes, nobles comme humbles, virent toutes des nuées pourpres ${ }^{151}$. On était alors le dernier jour du $1^{\text {er }}$ mois de 1227, année hinoto-i [Karoku 3].

Son Excellence du Dhyāna du Hosshōji [Michiie] était le fils du régent de Kogyokuin ${ }^{152}$ et l'oncle de l'empereur retiré Shijō ${ }^{153}$. Né d'une famille de ministres depuis des générations, il avait grandi dans la magnificence de la gloire, avait reçu en partage la bienveillance et embrassé la cause de la justice. Il affectionnait la sagacité et s'accordait aux autres. L'étendue de son savoir était inscrutable et sa bienveillance était infatigable. Son amour compatissant fixait la population dans un pays où régnait la voie. Sa retenue révérencieuse faisait atteindre au souverain une contrée sans faute. Sa fidélité était le bien des ministres de l'empereur. En tout, il répondait aux vœux du plus grand nombre. On le disait gratifié de la gloire ; on le disait tourné vers la puissance. L'empire lui adressait des louanges, le monde le chantait. Cependant, il vit une brusque décrépitude comme l'éclair et connut les anomalies des mirages. Il se convertit alors aux principes du Buddha et assit sa pensée dans la conversion du saint. À chaque fois qu'il rencontrait des maîtres de grande vertu et des moines éminents ${ }^{154}$ de toute secte, il faisait lire des sütra et des traités dont il scrutait la saveur à en épuiser la journée ${ }^{155}$. Il mit sa foi dans le maître de la Loi plus qu'en tout autre, car son intelligence pour comprendre autrui dépassait quiconque. Que ce fût pendant les trois mois d'été, pendant sept jours, pendant trois jours ${ }^{156}$, voire un seul jour, il avait l'habitude de demander au maître de la Loi de lui expliquer la doctrine que la pensée est pourvue de toutes choses dans le trichiliomégachiliocosme, pour en faire la quintessence de son esprit ${ }^{157}$. C'est pour

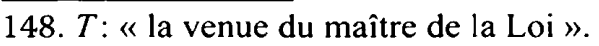

149. $T$ résume ainsi ces deux phrases: «L'aspect de son visage était comme de son vivant. »

150. $T$ : «Ce qu'on vit et entendit fit louer ».

151. $T:$ «À ce moment-là, de loin ou de près, tous virent des nuées pourpres. »

152. Kujō Yoshitsune (1169-1206). Voir le Sonpi bunmyaku, I, p. 89.

153. Mitsuhito (r. 1231-1242), fils de l'empereur Gohorikawa.

154. $T$ ne porte pas: « moines éminents ».

155. $T:$ « dont il scrutait les principes à des moments répétés ».

156. $T$ : « un mois ou un demi-mois ».

157. C'est la doctrine, propre au Tendai, de la présence en un instant de pensée du trichiliomégachiliocosme. 
Son Excellence du Dhyāna qu'il composa ${ }^{158}$ le Traité sur les principes de la Loi du Buddha ${ }^{159}$, la Méthode de samādhi de commémoration du Buddha ${ }^{160}$, la Méthode de méditation assise ${ }^{161}$, chacune en un volume, et l'Examen du sens du trichiliocosme, en deux volumes. Le style y est concis et la signification riche, sans jamais manquer de profondeur mystérieuse ${ }^{162}$. En outre il lui donna, pour nom d'adepte laïque, celui de Yuishin ${ }^{163}$.

Depuis le $10^{\mathrm{e}}$ mois de l'hiver de 1229 [Karoku 2], le maître de la Loi était allongé sur le lit, souffrant d'une maladie sans rémission. Le printemps de l'année suivante [Karoku 3], lorsque son état s'aggrava, Son Excellence du Dhyāna vint à son chevet ${ }^{164}$ accomplir ses dernières salutations. Il lui attribua 56 cho $^{165}$ de rizières à l'intérieur et à l'extérieur de deux villages de la province de Sanuki, afin de pourvoir perpétuellement aux dépenses du temple en subsistances pour les Buddha et en huile pour les lanternes. À la même époque, sur l'ordre du prince entré en religion Sonshō ${ }^{166}$, le premier fils du prince entré en religion Gotakakura, on lui fit présenter deux modèles de calligraphies autographes ${ }^{167}$ du Texte en mille caractères ${ }^{168}$. En les regardant, le prince s'exclama admiratif: «Bien qu'il soit immobilisé au lit par la maladie, sa calligraphie ne diffère en rien du temps jadis ${ }^{169}$ ! " Apprenant cela, le maître de la Loi déclara: «Arrivé au point de mourir, mon écriture ne peut plus changer ${ }^{170}$. »

158. $T$ : « il lui a donné ».

159. $T:$ : en deux volumes ».

160. $T$ : « en un volume».

161. Voir appendice $n^{\circ} 1$.

162. $T$ : «Le sens et les principes en sont remarquables et riches et épuisent au plus haut point les profondeurs des mystères. »

163. Yuishin koji 唯心/ $h_{i}^{\prime} \nmid$. Cette appellation fut sans doute donnée en référence à la doctrine de la naissance dans la Terre pure d'Amida grâce à la seule pensée: avant de mourir, Shunjō a donné à Michiie l'Exposé sur la Terre pure dans la seule pensée de Zongyi. Voir annexe IV.

164. $T:$ : il vint lui-même à son chevet ».

165. $T:$ : et plus ».

166. 筫性: Ses dates sont inconnues.

167. $T:$ : deux copies autographes ».

168. Le Senjimon T⿳亠口八.

169. $T$ : «L'élan de son pinceau ne s'est pas le moins du monde altéré avec le temps. »

170. $T$ : «Face à la mort, la seule chose qui ne change pas, c'est mon écriture. » 
$\mathrm{Au} 3^{\mathrm{e}}$ mois de la même année, il recopia [le poème] Ne pas passer un instant sans cet ami ${ }^{171}$, les Discours sur la Loi de Beifeng ainsi que sa Théorie sur la Terre pure dans la seule pensée ${ }^{172}$, qu'il donna à Son Excellence du Dhyāna ${ }^{173}$ - à l'époque, il était appelé Son Excellence l'ancien régent de Kujō ${ }^{174}$. Il lui donna en outre un exemplaire du Sütra du Lotus datant des Tang. [Son Excellence] le remercia [en ces termes] : "C'est bien humblement que je reçois cet exemplaire du sütra fondamental de l'école parfaite [du Tendai]. Bien qu'il expose la non-dualité originelle, il y a néanmoins transmission de vous à moi. Lors de nos retrouvailles dans la nature originelle, je ne compte que sur le village natal de la seule pensée [la Terre pure d'Amida]. " En outre, [il] rédigea ses Dernières recommandations pour le temple qu'il présenta à Son Excellence ${ }^{175}$. Celui-ci y acquiesça entièrement en y portant la mention: "Bien relu une fois le texte des Dernières recommandations. Il ne faudra pas y contrevenir. " Il copia de même des discours sur la Loi ${ }^{176}$ et les

171. Fukasetsuna mushikun 代刹那無此值, de Shanyin Yixian, voir première partie, p. 183, et n. 104. Le texte est édité dans Ishida 1972 (éd.), p. 400-401: le colophon porte qu'il a été recopié par Shunjō le 19 du premier mois et donné à Kintsugu.

172. Sur ce personnage, voir première partie, p. 173 et suivantes. Ses Paroles de la Loi peuvent être un recueil de textes de Zongyi incluant son Attestation religieuse (Shōhō 临法), [voir ibid., p. 184, n. 107] ou désignant celle-ci, si l'on en croit la mention qui est portée à la fin de cette dernière (Ishida 1972 (éd.), p. 400). L'Exposé sur la Terre pure dans la seule pensée expose la doctrine que, en raison de l'identité foncière de nature entre l'homme et Amida, c'est dans la seule pensée que l'on est pourvu principiellement de la Terre pure (yuishin rigu jōdo 唯心理! ! 浮上). Ces deux textes sont édités dans Ishida 1972 (éd.), p. 399-400: le premier texte a été copié par Shunjō le 10 du $3^{*}$ mois, et le second le 13 du même mois, tous deux à l'intention de Michiie. La filiation de Shunjō et de Beifeng Zongying, qui met l'accent sur la transmission de l'ésotérisme par Shunjō, est indiquée dans le Fozu tongji de Zhiban (1258-1269), $T, X L I X, n^{\circ} 2035$, p. 236bc [voir aussi la biographie de Zongyi, ibid., p. 233a].

173. Dans $T$, la mention «pour Son Excellence du Dhyāna... " apparaît en début de phrase.

174. Il résilia sa charge de régent en 1221 [Jōkyü 3], le 9 du 7ª mois. Voir le Sonpi bunmyaku, I, p. 86-87.

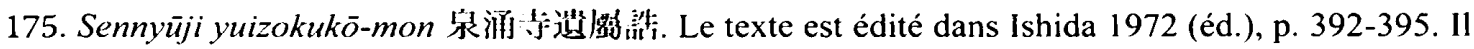
est daté du du 12 du $3^{\mathrm{e}}$ mois et porte la mention de Michiie.

176. Discours sur la Loi (hōgo 法涪i ) : terme générique désignant tout texte en prose ou en vers résumant les enseignements bouddhiques sous forme lapidaire, ou ceux d'un maître à destination de ses disciples, parfois placardés à l'entrée d'un monastère à titre de recommandations générales pour les adeptes. Sans doute s'agit-t-il ici d'un sermon sans plus de spécification. Voir la note suivante. 
donna à Shinkai ${ }^{177}$, à Jōshun ${ }^{178}$ et à Ryōshin ${ }^{179}$. Le supérieur Shinkai demanda à un peintre des Song, Zhou Tan, d'exécuter un portrait du maître ${ }^{180}$. Le maître de la Loi en composa lui-même l'éloge, qu'il signa ${ }^{181}$ en y portant ces mots:

Mon propre portrait

Fait dès le départ peur aux autres ${ }^{182}$.

Avec mon faciès émacié aux noirs sourcils,

Qui le tiendrait en estime?

Le premier jour du $3^{\mathrm{e}}$ mois intercalaire de la $3^{\mathrm{e}}$ année de Karoku [1227].

Éloge personnel de Shunjō, le moine qui a transmis la Loi en se rendant chez les Song.

Le $7^{\mathrm{c}}$ jour du même mois, à l'heure hitsuji [13 h-15 h], on fit retentir les tambours pour réunir la grande assemblée ${ }^{183}$. Revêtant la toge de dessus, il sortit de l'assemblée et fit brûler lui-même un encens réputé ${ }^{184}$. Quoiqu'il parût flétri, ses esprits n'en étaient pas moins vigoureux et la grande assemblée lui rendit ses dernières salutations. Chacun essuyait des larmes de douleur, en élevant des voix plaintives ou se

177. Tenpō rajoute shuso 闹坐: « le supérieur Shinkai ». La biographie de Shinkai 心游 figure dans le Ritsuen sōbōden, XI, DNBZ, 105, p. 253 ; et dans le Honchō kōsōden, LVIII, DNBZ, 103, p. 285. Son

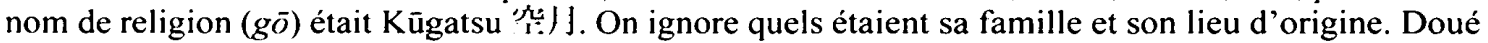
d'un grand talent, il était versé en waka mais se refusait aux honneurs en raison de sa modestie. Il étudia les doctrines exotériques et ésotériques, et alla rencontrer Shunjō à son retour de Chine, lequel lui enseigna la doctrine parfaite et soudaine du Véhicule unique [du Tendai]. Lorsque Shunjō inaugura le Sennyūji, il le nomma supérieur (shuso îj "Les trois vérités [du vide, du provisoire et du milieu] du trichiliocosme, la pensée actuelle en est pourvue dès l'origine et, comprenant qu'elle en est pourvue originellement, elle ne diffère pas du Buddha. De quelle façon le comprend-elle? Elle voit que l'authentique et l'illusoire sont simultanément tranchés. » Il poursuivit son activité de prédication des règles disciplinaires, notamment au Manjuin de la province de Settsu, à partir de l'ère Kangi (1229-1232).

178. La biographie de Jōshun 定僢 (?-1244) figure dans le dans Ritsuen sōböden, XI, DNBZ, 105, p. 253 ; et dans le Honchō kōsōden, LVIII, DNBZ, 103, p. 285-286. Son surnom (ji) était Raien 來緣. Il devint le troisième supérieur du Sennyūji. Au printemps 1237 (Katei 3), on lui demanda d'exposer les règles disciplinaires au Kairyūōji, à proximité de Nara, pendant les neuf décades [de la retraite d'été]. Il

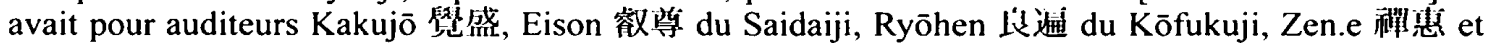
Genshun 源俊 du Kairyūōji. Puis il revient au Sennyūji. Il disparut le 5 du $3^{\mathrm{e}}$ mois de 1244 [Kangen 2], à un âge peu avancé.

179. On ignore les dates de Ryōshin 了 黄. Tenpō rajoute: « et d'autres ».

180. Ce portrait commandé au peintre Zhou Tanzhi (?-?) constitue, avec ceux de Daoxuan et de Yuanzhao rapportés de Chine par Shunjō (voir première partie, p. 183), l'ensemble des « portraits des trois patriarches de la discipline » (ritsusansozō 律 - 祙像) conservés au Sennyūji. Dans $T$, le nom de Zhou Tanzhi 阎圤之 est transcrit 咸扑之。

181. T omet «qu'il signa ».

182. Autre lecture possible: « Je réjouis les esprits [ou : les dieux] et j'apaise dès le départ les autres. "

183. Tenpō ne porte pas "grande », mais le terme apparaît avec ce qualificatif plus loin. Le terme “grande assemblée » (daishu 人浆) désigne l'ensemble des moines d'un monastère.

184. Tenpō supprime « réputé ». 
courbait en écourtant sa révérence. Il était impossible de décrire la scène que l'on avait devant les yeux. À ce moment-là, il déclara au supérieur ${ }^{185}$ Shinkai :

« J'ai réussi à exposer pour la dernière fois mon enseignement pour l'assemblée, en m'appuyant sur ceux du pays des Song, mais comme je tousse et que je suis sans voix, je ne puis plus l'expliquer. Il comporte des différences selon son degré d'explicitation, mais je vais résumer en un seul sa teneur finale. " Il trempa alors son pinceau et écrivit cette stance qu'il montra à l'assemblée en prononçant ces mots : «Assemblée plénière ! Je vais, à votre intention, vous léguer ces derniers propos quintessenciés :

Ne faire aucun mal

Accomplir tous les biens

De soi-même purifier sa pensée

Tel est l'enseignement de tous les Buddha ${ }^{186}$.

Voilà ce que tout un chacun sait.

Puis, après une pause, il déclara ${ }^{187}$ :

La sphère de la Loi en un instant de pensée est le vide.

Un instant de pensée dans la sphère de la Loi est le provisoire.

Fusion et coupure de la pensée et de la sphère est le milieu.

Au terme de la coupure de la pensée on dépasse le stade de Buddha. »

Le 8 du même mois, il trempa à nouveau son pinceau et composa cette stance d'adieu au monde:

Ma vie entière pleinement passée à l'étude

Des enseignements des sūtra et des traités

Et, d'un seul coup, le retrait

Dans l'apaisement, sans plus de terme !

Début du $8^{\mathrm{e}}$ jour du $3^{\mathrm{e}}$ mois intercalaire de la $3^{\mathrm{e}}$ année de Karoku [1227].

Le moine Shunjō, qui salue le supérieur et la grande assemblée ${ }^{188}$.

Il posa son pinceau avec cette stance ${ }^{189}$. Il se tourna aussitôt vers une représentation de la triade d'Amida, s'assit en médiation, fit l'añjalī et se coucha sur le côté droit, la tête au nord et le visage à l'ouest, afin d'expirer. Il avait alors soixante-deux ans, pour son âge profane, et quarante-quatre années de vie religieuse.

185. Tenpō omet « supérieur».

186. C'est la célèbre stance des règles communes aux sept Buddha du passé. Elle est citée par exemple dans le Mahāparīnirvānasūtra, auquel Shunjō se réfère plus loin (TSD, XII, nº 374, p. 451).

187. $T$ ajoute: «à nouveau ».

188. L'ensemble de ces dernières paroles a été recueilli sur un rouleau peint perdu un temps lors des troubles d'Ōnin ; il est édité dans Shunjō, p. 403-404.

189. $T:$ : Il jeta son pinceau ». 
À partir de l'aube du 9, la quadruple communauté ${ }^{190}$ se rassembla et, unanimement pénétrée de tristesse ${ }^{191}$, laissa déborder son émotion en déclarant: "Le maître est retourné au calme parfait, d'un seul coup et avec quelle rapidité ! Le bateau de la compassion a coulé ${ }^{192}$ et le flambeau de la sapience s'est éteint à jamais. » Le $10^{\mathrm{e}}$ jour, à l'heure $i n u^{193}$, on l'enterra sur la colline méridionale du temple. Lors des funérailles, religieux et laïcs emplirent la montagne et la vallée et pleuraient de douleur, comme pour le deuil de leurs père et mère. En vérité, il laisse maintenant une postérité.

J'ai brièvement relaté les actes [du maître de la Loi] sans faire de fioritures verbales, pour ne m'en tenir qu'aux seules relations véridiques.

\section{Éloge}

À en juger par son tempérament, le maître de la Loi surpassait les autres en intelligence prématurée, ses facultés mentales sont profondes. La montagne de ses talents était en vérité escarpée. On peut la contempler, on ne peut l'atteindre. L'océan de son intelligence était des plus profonds. On pouvait le traverser, on ne pouvait le sonder. La simplicité nourrissait son esprit, et c'était dans la pureté 194 qu'il enseignait aux êtres. Il tenait en droite estime la profondeur mystérieuse sans porter atteinte à la pauvreté pure. En dehors des images de Buddha et des volumes de sūtra, il n'était pas la moindre chose qui entrât dans sa vue, parmi le triple vêtement monastique et l'unique bol, il ne s'éreintait pas l'esprit pour se nourrir. Toutes les donations qu'il avait étaient employées pleinement aux édifications. Que ce soit le matin ou le soir, il prenait à cœur de diffuser la Loi et et de transmettre les règles disciplinaires. Qu'il s'endorme ou qu'il se réveille, il n'avait à la pensée que de pratiquer pour lui-même et de prêcher pour autrui.

Les actions bonnes ne laissent pas de traces. Les paroles de bien sont sans erreur. Il ne ménageait pas ses talents pour enseigner aux autres, et pour sauver les êtres ${ }^{195}$ il n'hésitait pas à aller au bout de ses forces. Il nettoyait ses pieds dans les vagues du Dhyāna et faisait résider ${ }^{196}$ sa pensée dans l'océan de l'enseignement. Sa conduite disciplinaire était rigoureuse. En vérité, les adeptes qui puisaient à son courant étaient, grâce à cela, comme une forêt. Les moines affluaient à sa porte et nombreux étaient ses fidèles laïques. En restant diserts, dignitaires et princes allaient à leur service dans le monde, et relevaient en hâte leur bonnet et leur robe pour s'assembler.

190. Les moines, les moniales, les laïcs et les laïques.

191. $T:$ " pleura de tristesse ».

192. $T:$ « s'est brisé ».

193. Soit de $19 \mathrm{~h}$ à $21 \mathrm{~h}$.

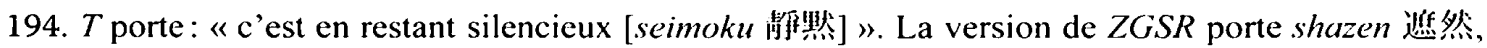
que je ne comprends pas (« de façon volubile »?, « dans la retenue »?).

195. $T$ : « pour donner de sa personne ».

196. $T$ : « et purifiait sa pensée ». 
En observant la frugalité, les fonctionnaires parachevaient leur personne et, en arrêtant les lances ornées, ils flottaient comme le vent. Japonais comme étrangers, nobles comme vils, gens de la cour comme gens du peuple, bons comme mauvais, tous révéraient sa vertu et suivaient son action convertissante. L'interrogeant sur la discipline, ils se pressaient en si grand nombre pour recevoir l'ordination qu'il était impossible de les dénombrer.

On l'entendait dire que l'enseignement saint comportait quatre-vingt mille [rubriques] mais que celles-ci se réduisaient à une ou deux, que pour le restant il fallait se conformer aux règlements disciplinaires et en son for intérieur cristalliser la compassion. Le Mahāparinirvāna-sūtra déclare: "Si l'on veut voir la nature de Buddha et réaliser le grand nirvānạ, il importe avec une disposition d'esprit profonde de cultiver et d'observer les règles pures. Si l'on vilipende les règles pures, on sera de la cohorte de Māra et non point mon disciple ${ }^{197}$. " Le Traité de la grande vertu de sagesse déclare: " $\mathrm{Si}$ un homme recherche un grand profit bénéfique, il devra fermement observer les règles, comme il choisirait un précieux trésor, comme il protégerait sa vie. Pour quelle raison? Il en va comme de la grande terre. Toutes les choses qui ont une forme physique subsistent en s'appuyant sur la grande terre. Il en va de même des règles, qui sont la résidence de toutes les bonnes choses. Cela serait comme vouloir marcher sans pieds, ou vouloir voler sans ailes, ou vouloir traverser sans bateau. Ce sont là choses impossibles. Si on veut obtenir un bon fruit sans les règles disciplinaires, il en sera ainsi. Si un homme a rejeté les règles, il aura beau s'adonner à l'ascèse en résidant dans les montagnes, en consommant des fruits ou en mangeant des herbes, il ne différera en rien des animaux ${ }^{198}$. "

Les périodes de vraie Loi et de Loi contrefaite sont maintenant passées, et celle de la Loi déclinante est déjà arrivée. L'enseignement authentique déclinant insensiblement, qu'est-ce qui surpasserait ces paroles ? Excellente entre toutes est ${ }^{199}$ la seule secte de la discipline. Croire soi-même qu'il est juste, pour un religieux, de ne pas observer les règles disciplinaires et de prendre sa pensée pour maître est une profonde affliction pour la grande Loi. C'est le début de la voie des impuretés. Quel bienfait que le maître de la Loi ait transmis cette secte pour perpétuer la vie de la Loi en ce monde souillé, et guider ceux qui errent dans la contrée pure ! Confucius a déclaré : "C'est l'homme qui est en mesure de développer la voie, et non pas la voie qui développera l'homme ${ }^{200}$. " Ce que Wang [Su] ${ }^{201}$ commente ainsi : "Qui a un grand talent l'agrandit parce que la voie le suit. Qui a un petit talent le rapetisse car la voie le suit. Aussi bien n'est-ce pas [la voie] ${ }^{202}$ qui peut développer l'homme. »

197. La citation semble être un résumé de $T, X I I, n^{\circ} 374$, p. 466c-468a ; n 375, p. 709b-711c (?).

198. $T, \mathrm{XXV}, \mathrm{n}^{\circ} 1509$, p. 153b. Voir la traduction correspondante d'Étienne Lamotte, qui tient compte du sanskrit restitué sous le chinois (Traité de la grande vertu de sagesse, II, p. 772-773).

199. T ajoute le caractère sha 者, qui explicite la structure de la phrase.

200. Entretiens de Confucius (Lunyu), XV, 28.

201. Wang Su 下:来 (195-256) des Wei.

202. «La voie » : restitué d'après $T$. 
Combien véridique est cette parole ! Si l'on occultait de tels hommes, comment pourrions-nous nous diriger dans le droit chemin ? Depuis que l'enseignement est apparu à son origine en Inde et que le courant de la Loi s'est écoulé dans les contrées de l'Est, les hommes d'intelligence remarquable qui ont quitté leur famille pour s'enquérir de la Loi sont légion, et les gens éclairés qui sont sortis de ce monde pour entrer dans l'autre se comptent par centaines. Parmi eux, ceux de riches talents et de vertu généreuse, qui développent la voie pour guider les êtres, vont voir de près le maître de la Loi ${ }^{203}$. On ne peut les qualifier de personnes profanes de peu de bien, mais on doit s'aviser qu'ils sont des avatars des saints aux grands pouvoirs.

Cela fait plus d'une dizaine d'années que je réside dans ce temple et que j'ai adopté pour principe directeur la secte des doctrines et de la discipline, que j'ai pris pour pratique de la Terre pure [le Buddha] Amitāyus, que j'ai eu entrevue [avec le maître] et ai écouté sa parole. Ce n'est pas un mince lien pour toute une vie. J'ai échangé des paroles avec lui et reçu ses enseignements, ce qui est une grande cause pour passer les éons. Je ne me suis pas encore sauvé mais accorde la priorité au salut des autres. Contracter un lien avec l'esprit de jadis, quand [le Buddha] était en ce monde, et avec la première captation pour guider [les êtres], telle est la pensée où je suis $^{204}$ maintenant après l'extinction [du Buddha]. Qu'en étant tout à ma foi, je ne laisse surgir des pensées de doute !

\section{Biographie du maître de la Loi Fukaki du Sennyūji}

[Colophon]

Le doyen du Sennyūji, Jōshun, le précédent maître du repentir du même temple, Shishin ${ }^{205}$, le précédent intendant Shiin ${ }^{206}$, ainsi que d'autres, m'ont donné l'ordre de composer cette biographie. Aussi, en partant d'un mince fil conducteur, j'en ai noté les grands traits. Je souhaite que le maître de la Loi y prête son regard merveilleux.

Le printemps de l'année kinoe-tatsu de Kangen [1244], dans la dernière décade. Révérencieusement écrit en saluant par l'adepte bouddhique Shinzui ${ }^{207}$.

203. Variante du $Z G S R J$ : « le maître de la capitale ».

204. $T:$ : le vœu que je conçois ».

205. Biographie dans le Ritsuen sōbōden, DNBZ, 105, p. 253 ; et dans le Honchō kōsōden, DNBZ, 103, p. 285.

206. Biographie dans le Ritsuen sōbōden, DNBZ, 105, p. 254 ; et dans le Honchō kōsōden, DNBZ, 103, p. 288.

207. Le colophon de $T$ ajoute: «Au début de l'automne de l'année kinoe-tatsu de Tenpō [1844], dans la dernière décade. // Révérencieusement écrit en saluant par l'adepte bouddhique Kakujun. " 


\section{ANNEXE I}

\section{Rituel de méditation assise. Shunjo $\overline{0}^{208}$}

Fermer les yeux sans voir les objets extérieurs.

Quand bien même on aurait les yeux ouverts, qu'on est comme si on ne voyait pas. Avec les oreilles, entendre les sons extérieurs sans les écouter. Voilà ce qu'est la pensée concentrée.

Observer les interdictions. Celui qui détruit les fautes et en son for intérieur cristallise la sapience authentique, observe à l'extérieur les règles d'interdiction. Ne pas concevoir de fautes en son corps, sa pensée et son esprit et, en son for intérieur, résider dans la pensée sans dichotomie. Quand bien même on verrait et on entendrait avec les yeux et l'ouïe, qu'en aucun cas il n'y aurait pensée dichotomisante. Une absence complète de pensée dichotomisante, bien que l'on voie avec les yeux et entende avec l'ouïe : voilà ce qu'on entend par cristalliser en son for intérieur la sapience authentique.

Parmi les six commémorations ${ }^{209}$, le don, les règles et les cieux sont relatifs à la vérité intérieure et aux affaires extérieures. Les cieux où l'on commémore les rétributions de bonnes causes sont les cieux d'aspect extérieur. Ce sont des cieux de vérité intérieure première.

Si l'on fait offrande aux Trois Joyaux avec les quatre offrandes ${ }^{210}$, il s'agit d'un don d'aspect extérieur. Le donateur et le donataire, ainsi que la chose donnée, réalisent trois offrandes de façon inconcevable. Ce sont des dons authentiques, immaculés et purs.

En outre, dans la méthode de méditation assise, il est toujours une divinité tutélaire. En Chine, il est le roi-dragon du Tianmushan, qui protège en particulier ceux qui s'adonnent à la méditation assise. Ce dieu-dragon est un avatar de Kannon Canḍīîn.

Shunjō, le moine qui s'est rendu en Chine pour transmettre la Loi.

J'ai entendu dire qu'un autographe du maître national sur le présent rituel de méditation assise se trouvait entreposé au pavillon Shōmon.in du Tennōji.

Les articles précédents sont restés dans l'ouïe et la vue des hommes, mais le temps passant, on en a sans doute perdu l'origine. C'est la raison pour laquelle j'en ai noté les grands traits. Quant aux détails, des hommes éclairés ultérieurs en feront état.

Le $11^{\mathrm{e}}$ mois de 1718 , écrit par le vieillard de soixante-treize ans, feu Takugan du Sennyūji.

208. Ishida Mitsuyuki, Shunjō, p. 407.

209. Envers le Buddha, de la Loi, de la communauté, les règles, le don, les dieux (buppōsō kaiseten 佛 法僧戌施天) (Sütra de Samantabhadra, Puxianjing 普賢經)。

210. Les quatre offrandes au Buddha et à la communauté, qui consistent en vêtements, en nourriture, en literie et en médicaments.

211. Avalokiteśvara féminin sous la forme terrible de Durgā, Jūndai kannon 准提観点. 


\section{ANNEXE II}

\section{Recommandations en sept articles [Shichikajō seikai]}

Dans ses Recommandations en sept articles (Shichikajō seikai), Hōnen a dicté une série d'interdictions et prononcé des injonctions touchant la discipline, auxquelles certains de ses disciples, tenants de la pratique du Nenbutsu, passaient pour contrevenir, à la suite d'une accusation venant du Hieizan. Ce texte est une réponse à ces critiques, qu'il aurait fait contresigner par ses disciples les plus fidèles, au nombre de cent quatre-vingt-dix, durant trois jours, les 7,8 et 9 du $11^{e}$ mois de 1204 [Genkyū 1], si l'on en croit la tradition admise, qui semble assez fiable. Il a présenté ses Recommandations au supérieur du Tendai du Hieizan, Shinshō (mort en 1230). L'original est conservé au Nison.in de Saga, à Kyōto, mais on a émis des doutes quant à sa stricte authenticité. On admet néanmoins, que cette version, contemporaine de Hōnen, refléterait assez fidèlement sa pensée. Tout du moins constitue-t-elle un document d'époque. D'autres, nettement suspectes, font des ajouts, comme un serment prêté devant les divinités et les Buddha en introduction, ou portent le titre de "supplique " [kishōmon], qui est controuvé. Nous nous sommes fondé sur l'édition de la version du Nison.in de la NST, 10, p. 232-235 et 283-285, ainsi que celle du Shōwa shinshū Hōnen shōnin zenshū, p. 787-793.

Je déclare la chose suivante à tous les pratiquants ermites [shōnin] de l'invocation du Buddha qui se donnent pour être de mes adeptes.

[Premier article] À ceux qui, sans s'être enquis du moindre texte - fût-il d'une phrase - , réfutent le Shingon ainsi que [la pratique de] l'apaisement et de l'examen mentaux [le Tendai], et qui vilipendent les buddha et les bodhisattva autres [qu'Amida], il faut porter un coup d'arrêt.

S'agissant d'une voie qu'on veut établir ou qu'on cherche à réfuter, il faut en passer par [le long chemin] de l'étudiant et ne pas en être au stade d'un ignare. En outre, vilipender la Loi authentique revient déjà à être exclu du vœu d'Amida ${ }^{212}$. Ils auront en rétribution de chuter dans l'enfer Avīci. N'est-ce pas là le comble de la stupidité ?

[Deuxième article] À ceux qui sont ignares et qui aiment à se quereller avec ceux qui ont le savoir ou avec des personnes qui s'adonnent à des pratiques autres [que le Nenbutsu], il faut porter un coup d'arrêt.

Discuter des principes doctrinaux [rongi] est le propre de ceux qui ont le savoir et n'est a fortiori pas à la portée d'un ignare. En outre, là où il y a querelle, se déchaînent toutes les passions. Celui qui sait s'en éloigne de cent yojana. À combien plus forte raison devrait le faire ce pratiquant du seul Nenbutsu !

212. Référence au Sütra d'Amitāyus, vol. I, $48^{\circ}$ vou: «Tant que les êtres ne sont pas nés [dans la Terre pure], je ne saisirai pas l'éveil juste. J'exclus toutefois ceux qui ne font que perpétrer les cinq fautes irrémissibles et vilipender la Loi authentique. » ( $T$, XII, n³60, p. 268a, 27-28) 
[Troisième article] À ceux qui, vis-à-vis de personnes qui ont des opinions et des pratiques différentes, avec un esprit borné et des attachements unilatéraux leur déclarent qu'il importe d'abandonner leurs pratiques de base, les prennent en détestation et les ridiculisent, il faut porter un coup d'arrêt.

Dans la manière de cultiver la voie, il y a pour chacun seulement à s'adonner aux pratiques qui valent pour soi-même sans dénier a fortiori celles qui valent pour autrui. Dans la Détermination essentielle de la contrée occidentale, il est déclaré: "Autant que faire se peut, il importe d'avoir des pensées de respect à l'égard de ceux qui ont des vues et des pratiques différentes. Si on les méprise, infinie sera la faute qu'on aura commise ${ }^{213}$. » Comment pourrait-on s'opposer à cette règle ? Qui plus est, le maître Shandao a lui-même fortement réprimandé cette attitude. Continuer à ignorer les injonctions des maîtres patriarches, c'est le comble des ténèbres.

[Quatrième article] Dans la secte du Nenbutsu, sous prétexte qu'il n'y a pas de pratiques disciplinaires, on promeut exclusivement la luxure, l'alcool et la nourriture carnée et, en qualifiant de personnes aux pratiques mélangées ceux qui, rarissimes, observent les règles, les gens qui s'appuient sur le vœu fondamental d'Amida enseignent qu'il n'y a pas à avoir peur de commettre du mal. Il faut y porter un coup d'arrêt.

Les règles disciplinaires sont la grande terre ${ }^{214}$ de la Loi du Buddha. Diversifiées sont les nombreuses pratiques, mais elles sont tout entières dans ces [règles]. C'est ce que le maître Shandao [appelait] " lever les yeux sans regarder les femmes ${ }^{215}$ ". Le sens de tels comportements excelle parmi les règlements de la discipline fondamentale. Si ceux qui s'adonnent aux actes [de la Terre] pure ne les suivent pas, ils manqueront aux enseignements légués par le Tathāgata et se détourneront en particulier des chemins suivis par les maîtres patriarches. Il n'est, en somme, aucun fondement [à de tels agissements contre les règles].

[Cinquième article] Aux gens stupides qui ne peuvent pas même distinguer le vrai du faux, qui se départissent des enseignements saints, qui passent à côté de l'enseignement de leur maître, qui font état de leurs thèses propres selon leur caprice, qui ourdissent des querelles à tort et à travers, qui sont la risée des personnes sages et induisent en erreur les pauvres d'esprit, il faut porter un coup d'arrêt.

On dirait que Mahādeva l'inculte ${ }^{216}$ est rentré dans notre pays pour y exposer des thèses viciées à tort et à travers, et qu'on a affaire aux quatre-vingt-quinze voies hérétiques. Il faut s'en affliger au plus haut point!

213. Citation abrégée de Guiji ( $T$, XLVII, no 1964 , p. 109c $\left.{ }^{20-21}\right)$.

214. La grande terre : le fondement.

215. L'expression est notamment citée dans le Longshou zengguang jingduwen, $T$, XLVII, $n^{\circ} 1970$, p. $266 \mathrm{c}^{16-17}$

216. L'hérétique qui, selon la tradition, cent ans après le Parinirvāna du Buddha, aurait professé cinq thèses nouvelles qui auraient été à l'origine de la scission de la communauté bouddhique en Doyens et en ceux de la Grande assemblée? 
[Sixième article] Aux ignares qui ont les facultés obtuses et qui affectionnent particulièrement les homélies mais qui, ignorant la Loi authentique, professent tout un ensemble de doctrines viciées et prêchent aux religieux et aux laïcs ignorants, il faut porter un coup d'arrêt.

Devenir un maître sans avoir la sapience est interdit par le Sütra du Filet de Brahmā. Les êtres obscurantistes qui veulent faire montre de leur propre talent, prennent l'enseignement de la Terre pure pour un art, convoitent le renom et les profits, se mettent en quête de donateurs, prêchent des faussetés selon leur caprice et induisent en erreur les gens du monde, tombent dans la faute particulièrement grave de tromper la Loi : ne sont-ils pas au contraire des traîtres aux pays ?

[Septième article] Ceux qui, en professant des doctrines viciées qui n'ont rien à voir avec l'enseignement bouddhique et les tiennent pour la Loi authentique, prétendent indûment que c'est une prédication de maître-modèle, il faut porter un coup d'arrêt.

Ces thèses, fussent-elles prêchées par un seul individu, font, une fois accumulées, un ensemble de maux qui rejaillissent sur ma seule personne. Elles souillent le texte des enseignements d'Amida et font grandir la mauvaise réputation des maîtres. Il n'est rien qui surpasse le comble de ces maux.

Tels sont les sept articles que j'ai exposés dans leur ordre. Les disciples qui voudraient un tant soit peu étudier les textes des enseignements doivent en premier lieu être au fait de ces principes [énoncés]. J'ai durant des années pratiqué le Nenbutsu mais j'ai [toujours] suivi l'enseignement saint, sans jamais me permettre d'aller à l'encontre de l'esprit des autres ni de scandaliser l'opinion publique. Ce faisant, j'ai jusqu'à présent passé trente années sans encombre ${ }^{217}$. Mais, ces derniers temps, depuis une dizaine d'années, des individus ignares et sans vergogne sont fréquemment venus. Non seulement, ils portent tort à la pratique [de la Terre] pure d'Amida, mais encore ils souillent la Loi léguée par Śākyamuni. Comment n'y ajouterait-on pas de claires réprimandes? Dans ces sept articles, je n'ai presque pas pu faire état en détail des faits importants ou menus parmi les choses iniques. De façon générale, il faut en toute humilité s'interdire de commettre des choses aussi insensées. Les individus qui en outre continueraient à contrevenir à ces règlements ne font plus partie de mon école, mais de la cohorte de Māra. Ils n'ont plus à venir à mon ermitage. Dorénavant, dès que chacun entendra parler [de tels agissements], il aura sans faute à le faire savoir. On ne devra plus dès lors se trouver en compagnie [d'un tel fauteur], sinon on s'exposera à passer pour partager ses vues. Ceux qui se rendraient coupables de telles fautes n'auront pas à se mettre en colère contre leurs coreligionnaires ni à en vouloir à leurs maîtres. Le principe qu'on ne récolte que ce que l'on a semé se trouve uniquement dans sa propre pensée. C'est pourquoi je convoque aujourd'hui les pratiquants [du Nenbutsu] dans toutes les régions pour les rassembler dans ma cellule et leur faire ces injonctions. J'ai passé des années à

217. Hōnen compte trente années à partir du moment de sa conversion, en 1174 [Angen 1]. 
m'affliger de rumeurs, ne sachant, à propos des moindres bruits qui me revenaient, s'il s'agissait de fautes assurément commises par quelqu'un. Mais comme je ne pouvais garder le silence plus longtemps, j'ai conçu le plan d'interdire [ces agissements] autant que j'en avais les moyens. C'est la raison pour laquelle j'ai rédigé le présent texte d'intention afin de le montrer à mes disciples.

Le $7 \mathrm{du} 11^{\mathrm{e}}$ mois de 1204 [Genkyū 1].

Le moine Genkū [paraphe]

\section{ANNEXE III}

\section{Les règles disciplinaires selon Kūkai}

Kūkai a donné des recommandations (yuikai) à ses disciples après avoir donné l'onction (kanjō) à un grand nombre de moines au Takaozanji de Kyōto, le 14 du $12^{\mathrm{e}}$ mois de 812 (Kōnin 3). Lorsqu'il donna ses instructions à Takao le $14 \mathrm{du}$ $12^{\mathrm{c}}$ mois de 812 [Kōnin 3], Kūkai mentionna la liste de ses adeptes à qui il avait conféré l'onction dans un registre [Kanjō rekimei 濯頂暦名]: ils étaient 190 à recevoir l'eau du serment de l'onction de souvenance du mantra et à apprendre le mantra des dix-huit voies, c'est-à-dire l'onction du monde de matrice ; s'y trouvaient Saichō, des moines du Tōdaiji, du Saidaiji, du Gangōji, du Daianji, du Kōfukuji, du Yamashinadera, ainsi que d'autres religieux de Nara. Il y distingue comme ici quatre catégories d'adeptes: l'assemblée des religieux par excellence [daisōshū 大僧衆], c'est-à-dire de ceux qui ont reçu les règles complètes, celle des novices [shamishū 沙弥衆], celle des laïcs [gonjishū 近士衆] et celle des desservants [dōji 童子]. Il avait déjà procédé à l'onction du monde de diamant le $15 \mathrm{du} 11^{\mathrm{e}}$ mois de 812 à Takao, à Saichō et d'autres moines. Parmi ses disciples, on trouve dix-sept noms, dont ceux de Taihan, Enchō et Kōjō, qui n'avaient pu recevoir l'onction du monde de diamant et pour qui il l'a effectuée le 6 du $3^{\mathrm{e}}$ mois de 813 [Kōnin 4]. C'est à la suite de cette série d'ordinations ésotériques selon les deux mondes que Kūkai prêche des recommandations faisant état de ses idées sur les règles disciplinaires, devant un public étendu puisqu'il comprend des moines aguerris autant que des novices. C'est une séance d'uposatha, puisqu'elle a eu lieu au milieu d'un mois.

Le texte est daté de 813 , dernier jour du cinquième mois, et est passé par la suite sous le titre de Dernières recommandations (Goyuigō 御遺告). Parmi les nombreux textes attribués à Kūkai qui portent ce dernier titre, et dont l'authenticité est souvent douteuse, ce texte-ci est le premier en date et semble authentique, mais son titre semble frauduleux, bien que certains auteurs le trouvent naturel ${ }^{218}$ : Kūkai ne disparaîtra que vingt-trois ans plus tard, et rien dans ce texte ne laisse penser qu'il en est à ses derniers moments. Il analyse les questions de l'obtention du fruit de Buddha à même ce corps (sokushinjōbutsu 即身成佛), du respect des règles disciplinaires exotériques et ésotériques, de la filiation de maître à disciple, du samādhi du vénéré fondamental, du salut par le double profit (pour soi-même et autrui) et des quatre bienfaits (shion 四恩). 
Kūkai fait dans ce texte référence aux adeptes de toutes les sectes (les disciples du Buddha) et à ceux de l'ésotérisme Shingon? (les fils du diamant et du Lotus, c'est-à-dire des deux mandala): ce sont tous les moines des écoles de Nara et du Hieizan qui sont réunis, et auxquels Kūkai veut insuffler l'esprit du maṇạala, c'està-dire des règles ésotériques qui, loin d'entrer en contradiction avec les autres, viennent les couronner: Kükai se veut œcuménique.

Ce texte revêt une importance capitale: il montre en effet comment Kūkai avait résolu le problème des règles disciplinaires avant que Saichō ne proposât la solution qu'on lui connaît, celle de la réception des règles " de bodhisattva ", dites règles parfaites et complètes, comme suffisantes à l'acquisition de l'état de moine, sans passer par l'estrade d'ordination du Tōdaiji, ce qui requérait la réception des règles plénières. Le système de formation religieuse qui se fonde sur le samādhi du vénéré fondamental et sur la théorie des quatre bienfaits, donnera le ton de ses ouvrages théoriques postérieurs, comme la Signification de l'accession à l'état de Buddha à même ce corps (Sokushinjöbutsugi 師身成佛義) et le Traité sur la distinction des deux enseignements exotériques et ésotériques (Benkenmitsu nikyōron 辯顯密二-教 論), qui définiront les idéaux de la vie religieuse et des activités sociales auxquelles s'adonne le religieux.

Le système des règles instauré par Kukai combine des règles exotériques, qui instaurent des règles de base pour chacune des quatre parties de l'assemblée religieuses (moines et laïcs, masculins et féminins), ainsi que d'autres catégories d'adeptes possibles (auditeurs, bodhisattva), et des règles ésotériques qui couronnent les précédentes sur un plan supramondain, en mettant sur un pied d'égalité dans un esprit unique la pensée individuelle, celle des êtres et celle des Buddha. Si on le compare au système de Saichō, celui de Kūkai met les règles de Buddha sur un plan supramondain au-dessus des règles « de bodhisattva », le mot de bodhisattva étant à comprendre ici dans le sens de simple candidat à l'éveil et non pas d'être accompli, comme cela se passe chez Saichō.

\section{Dernières recommandations (Yuikai)}

[Les disciples issus de l'école Shingon, en raison de leurs actes antérieurs, sont au comble des illusions de l'égarement. Il me faut les prévenir par ce texte. Aussi bien doivent-ils toujours le conserver à leur chevet comme adjuvant pour réveiller leur esprit ${ }^{219}$.]

Je déclare la chose suivante à tous les disciples. À l'origine, la culture de la voie du moine est d'escompter [obtenir] le fruit de Buddha, sans rechercher a fortiori la maison des souverains universels, de Brahmā ou d'Indra. À combien plus forte raison les fruits de peu des humains ${ }^{220}$ ! On n'arrivera pas à traverser au loin [ce monde de la transmigration] en ayant conçu la pensée de l'éveil, si l'on ne [part] pas $\mathrm{du}$ [bon] pied. On ne parviendra pas à se diriger sur la voie de Buddha, si l'on ne

219. Cette phrase est un ajout postérieur, d'origine inconnue.

220. C'est-à-dire les honneurs et les fonctions dans le monde profane. 
réside pas dans les règles disciplinaires. Il importe de toujours recevoir et observer fermement les deux règles de l'exotérisme et de l'ésotérisme, et de rester pur sans les violer. Ces [règles de] l'exotérisme et de l'ésotérisme sont les trois prises de refuge, les huit règles ${ }^{221}$, les cinq règles ainsi que celles des auditeurs et des bodhisattva. Chacune des quatre assemblées ${ }^{222}$ a des règles disciplinaires de base. Les règles ésotériques sont les règles d'égalisation ${ }^{223}$. On les appelle également " règles de Buddha [bukkai 佛戒] », de « règles de la conception de la pensée de l'éveil [hotsubodaishinkai 發菩提心戒] ${ }^{224} »$ ou 《règles inconditionnées [muikai 無爲戒] ${ }^{225} 》$.

Toutes ces règles ont pour fondement les dix biens ${ }^{226}$. Ceux-ci sont les trois relatifs au corps, les quatre concernant la parole et les trois touchant à la pensée. Si on en ramène les développements à leur origine, elles prennent pour fondement la pensée une [isshin - 心]. La nature de la pensée unique ne diffère pas du Buddha. Ma pensée, celle des êtres et celle du Buddha ne diffèrent toutes trois en rien ${ }^{227}$. Dès qu'on réside dans cette pensée, on cultive la voie de Buddha. Lorsqu'on monte sur ce véhicule de joyaux, on atteint directement l'aire de l'éveil. L'examen de

\footnotetext{
221. Ce sont les cinq règles s'appliquant aux laïcs, ainsi que trois autres propres aux religieux. Cet ensemble de huit règles est à observer pendant vingt-quatre heures, les jours de l'uposatha, par les laïcs, hommes ou femmes. Ce sont : $1^{\circ} l^{\prime}$ interdiction de tuer un être vivant ; $2^{\circ}$ l'interdiction de voler ; $3^{\circ}$ l'interdiction d'avoir des relations sexuelles $; 4^{\circ}$ l'interdiction de mentir $; 5^{\circ} l^{\prime}$ 'interdiction de consommer de l'alcool $; 6^{\circ} l^{\prime}$ interdiction de se parer, de se maquiller et de s'habiller luxueusement ou de manière ostentatoire, ou encore d'assister à des spectacles de chant et de danse ; $7^{\circ}$ l'interdiction de s'asseoir sur un siège élevé, ou de s'allonger pour dormir dans le confort ; $8^{\circ}$ l'interdiction de s'alimenter après midi. Les laïcs les observent les $8,14,15,23,29$ et 30 de chaque mois.
}

222. Religieux et religieuses, laïcs et laïques.

223. Samaya-kai: samaya a ici le sens d'égalisation, de mise sur un pied d'égalité des êtres et des Buddha. Grâce à ces règles, l'adepte se fond dans tous les Buddha pour être égal à eux, obtenir leur sapience et se libérer de tous les maux (Commentaire au Mahāyānasūtra, Darijingshu 人认經疏).

224. Les règles pour susciter la pensée d'éveil dont tout être est pourvu originellement.

225. Les règles suprêmes, qui se fondent sur l'esprit d'altruisme, par-delà tout formalisme.

226. La liste des «dix biens » se compose comme suit : $1^{\circ}$ ne pas tuer d'être vivant; $2^{\circ}$ ne pas voler $; 3^{\circ}$ ne pas s'adonner à la luxure $; 4^{\circ}$ ne pas prononcer de parole frauduleuse $; 5^{\circ}$ ne pas avoir de double langage $; 6^{\circ}$ ne pas médire $; 7^{\circ}$ ne pas proférer de paroles oiseuses ; $8^{\circ}$ ne pas entretenir de désirs concupiscents $; 9^{\circ}$ ne pas être haineux $; 10^{\circ}$ ne pas avoir de vues erronées. Les trois premières concernent les actes du corps, les quatre suivantes ceux de la parole et les trois dernières ceux de la pensée.

227. C'est une variante de la stance du rien-que-pensée qui serait issue du Sūtra de l'Ornementation fleurie, chapitre des « Dix stades », dont le succès fut particulièrement grand au Japon.

Selon l'interprétation de Kükai, la pensée est celle de l'éveil dont l'individu est originellement pourvu. La pensée des êtres est la pensée authentique [shinshin 悬心] selon l'ornementation fleurie, c'est-àdire la nature de Buddha dont tout être est pourvu dès l'origine, ce qui la met sur un pied d'égalité avec la pensée de Buddha. Ces trois pensées sont donc égales.

Kükai reçut de son maître Huiguo un enseignement de teneur similaire : «Connaître sa propre pensée, c'est connaître la pensée de Buddha. Connaître la pensée de Buddha, c'est connaître la pensée des êtres. Savoir que ces trois pensées sont égales est qualifé d'éveil par excellence [daikaku 大腎]. Si l'on veut obtenir l'éveil par excellence, il importe d'assimiler l'enseignement de l'auto-attestation de tous les Buddha. » (Seireishü, vol. IX, $\mathrm{n}^{\circ}$ 98, NKBT 71, p. 406: «Qu'il importe d'enjoindre à l'assemblée concernée de copier les 35 rouleaux du trésor de la Loi de l'ésotérisme. ») 
la sapience suprêmement supérieur ${ }^{228}$ est le chemin de la réalisation de l'état de Buddha à même ce corps. L'examen de la sapience supérieur ${ }^{229}$ réalise le fruit au cours des trois grandes [périodes immenses]. L'examen de la sapience moyen ${ }^{230}$ est le Véhicule des Buddha-pour-soi, et celui de la sapience moyen est le Véhicule des Auditeurs ${ }^{231}$. Si l'on n'est pas pourvu de toutes ces règles plénières, l'œil de la sapience sera dans l'obscurité ${ }^{232}$. C'est en s'avisant de ce sens qu'il importe de garder son œil et sa vie [charnels]. Ou plutôt, c'est quitte à perdre sa vie corporelle qu'il importe de ne pas violer ces règles. Si on les viole consciemment, on ne sera plus un disciple de Buddha, ni un fils de diamant, ni un fils de fleur de lotus ${ }^{233}$, ni un fils de bodhisattva, ni un fils d'auditeur, ni mon disciple non plus. Je ne serai moimême plus son maître. En quoi différera-t-on alors d'une motte de tourbe ou d'un bois brisé ?

La voie de maître à disciple est proche parente de celle de père à fils. Le père et le fils sont proches parents par les os et la chair: ils sont seulement l'amour d'une vie et sont liés à la vie et à la mort. L'amour de maître à disciple est intimité mutuelle dans le sens de la Loi, il délivre de la douleur et procure le bien-être de façon mondaine et supramondaine ${ }^{234}$. Comment pourrait-on les comparer ? C'est pourquoi je vous les indique sur les voies trompeuses de traverse en vous en enjoignant instamment.

$\mathrm{Si}$ vous suivez mes recommandations, vous serez en conformité avec les règles disciplinaires des Buddha des trois temps. Telle est la prédication des Buddha. Ce ne sont pas mes paroles propres. Tous les moines qui ont reçu les règles plénières, les novices, les laïcs et les desservants ${ }^{235}$ doivent mettre en pratique ces règles, cultiver consciencieusement le samādhi [de non-dualité avec] le vénéré fondamental,

228. Un des examens mentaux des Quatre Véhicules, où l'on envisage le principe de la coproduction conditionnée.

229. Celui qui permet de réaliser rapidement l'éveil dans sa condition corporelle actuelle.

230. Un des examens mentaux des Quatre Véhicules, celui des Buddha-pour-soi, qui ne permet pas d'atteindre l'état de Buddha.

231. Un des examens mentaux des Quatre Véhicules, celui des Auditeurs, qui ne voient pas même la nature de Buddha.

232. Il ne verra pas le véritable aspect des choses.

233. Deux interprétations sont données comme possibles: le diamant et la fleur de lotus désignent le monde de diamant et celui de la matrice de grande compassion ; le Buddha, le diamant et le lotus correspondent aux trois sections du monde de la matrice.

234. Dans son testament, Amoghavajra marque aussi la différence substantielle qu'il y a entre les liens de famille et ceux de maître à disciple: " La voie de maître à disciple est intime affectivement dans le sens de la Loi. Elle n'a rien à voir avec les os et la chair, et diffère du tout au tout de la profanité. Vous aussi, si vous vous appuyez sur mes paroles, vous serez mes fils dans la Loi. Si vous vous écartez de mes ordres, vous ne serez plus en affinité avec la Loi. »

235. Lorsqu'il a donna ses instructions à Takao au $12^{\mathrm{e}}$ mois de 812 [Kōnin 3], Kūkai consigna dans un registre (Kanjō rekimei 灌頂暦名) la liste des adeptes à qui il avait conféré l'onction en distinguant, tout comme ici, quatre catégories d'adeptes: l'assemblée des religieux par excellence (daisōshū 大俻

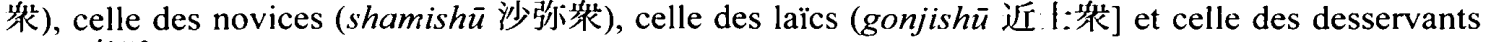
(dóji 点 f $^{*}$ ). 
dépasser rapidement les trois attachements fallacieux ${ }^{236}$, réaliser au plus vite l'éveil parfait, accomplir parfaitement le double mérite ${ }^{237}$ et procurer le salut des quatre bienfaits $^{238}$. Ceux qu'on appelle les bodhisattva, comment seraient-ils des hommes d'exception ${ }^{239}$ ! Si l'on contrevient à mes recommandations, on se détournera de l'enseignement de tous les Buddha. Tels sont ceux qu'on qualifie de damnés [icchantika]. Pour longtemps engloutis dans l'océan des douleurs, en quel temps donc pourront-ils en réchapper? Moi non plus je ne m'adresse pas à vous en restant pour toujours avec vous. Allez sans stationner! Allez sans stationner!

Le dernier jour du milieu du printemps [le $5^{\mathrm{e}}$ mois] de 813 [Kōnin 4].

\section{ANNEXE IV}

\section{Exposé sur la Terre pure dans la seule pensée ${ }^{240}$}

Une fois que l'on a déjà réalisé l'identité sans dualité avec Vairocana,

C'est en vérité en s'appuyant sur [le principe] que le trichiliomégachiliocosme

[est en un instant de pensée depuis les temps sans commencement,

Que l'on s'avise de l'identité de nature entre soi-même et la Terre [pure]

Ainsi que de la non-dualité entre le saint et le profane.

Tous les Buddha réalisent [l'éveil] en adéquation à la nature [des choses],

Tandis que tous les êtres errent en se détournant de cette même nature :

Leurs actes fallacieux prolifèrent

Et leur transmigration est sans fin.

L'esprit des Buddha, en les prenant en compassion, leur montre cette nature

[afin qu'ils la cultivent.

Une fois qu'est mise en évidence de façon directe la nature foncière,

La source authentique de Vairocana

Est perpétuellement apaisée et fusionne de manière parfaite.

Ayant réalisé l'être sublime,

[Les êtres] s'appuient, sans en différer, sur la nature

Pure et calme qui,

Dès l'origine, s'étend à la sphère de la Loi.

$\mathrm{N}$ 'ayant pas fini de le mirer par réflexion,

Le principe se manifeste et oubliés sont les affects illusionnants,

236. Attachements grossiers, subtils et très subtils : il s'agit, respectivement, de l'erreur de l'attachement au moi, de celle de l'attachement aux choses [dharma] et de celle de l'illusion. On peut les trancher en une seule vie, au lieu d'avoir à passer par des éons incalculables.

237. Pour soi-même et pour autrui.

238. Les quatre bienfaits sont ici ceux du père et de la mère, des êtres, du souverain et, enfin, du Triple Joyau. On voit que Kükai fait passer les liens mondains et sociaux avant les éléments religieux.

239. «Ceci vaut pour les bodhisattva, à combien plus forte raison pour les autres hommes ! " Ou encore : "Tels sont les bodhisattva, à combien plus forte raison cela s'appliquera-t-il aux autres hommes!" L'expression ijin 異人 peut avoir le sens « d' hommes d'exception » ou " d' hommes autres ».

240. Titre donné par la version de l’Université Ryūkoku. Texte dans Ishida, p. 400. 
L'activité de l'efficace se duplique

Et tout est la Loi originelle.

Ce qu'on appelle le vaste et l'étroit,

Le supérieur et l'inférieur sont inconcevables.

Le pur et l'impur ne peuvent être scrutés de façon exhaustive.

Quoique le saint et le profane aient une nature d'éveil égale,

Il est des différences dans la façon dont le vœu et sa pratique s'adaptent aux [ressorts [des êtres].

Amida parfait la réalisation de la sphère de la Loi et orne de façon spécifique la

[Direction de l'Ouest,

Les êtres manifestent les choses dont ils sont pourvus de nature,

Et se pourvoient de façon spécifique de la Contrée de bien-être.

Une fois Amida en adéquation avec la nature [authentique des choses],

Comment les êtres qui ont la force de vœu ne seraient-ils pas tous dans l'objet

[de l'authentique nature grâce à leur pensée ?

C'est tout uniment qu'ils s'appliquent à s'élancer

Et leur vœu est d'être captés [par Amida].

La nature originelle est, dès le départ, présente en eux, et son déploiement

[dépend des conditions.

J'ai goûté cette parole :

C'est selon le principe qu'il n'est rien que de la pensée, que l'on est pourvu de [la Terre pure,

Et que les sentiments de douleur et de bien-être se trouvent ici ou là.

J'atteinds le rien-que-pensée car je n'ai pas encore oublié [ce principe].

Je fais le vœu de naître dans la Contrée où l'on nourrit le bien-être,

La naissance n'est pas en dehors de la nature et ne fait que réaliser ce dont

[chacun est originellement pourvu.

En restant dans sa pensée concentrée seule, on ne sera pas sans épouser

[les desseins [du Buddha],

L'esprit vaquera dans le Domaine aux joyaux [la Terre pure] et l'on sera le

[témoin visuel de Son attitude compatissante,

Et c'est spontanément qu'on parcourra les dix directions pour servir tous les

[Buddha.

Comment donc les vœux et les pratiques aussi de soi-même que des autres ne

[s'accompliraient-ils pas?

Le maître de la Loi du Japon Shunjō, au cours des huit années qu'il a passées [en Chine], a vu comment dans les réunions la compréhension et la pratique [des participants] étaient sublimes et inébranlables du début jusqu'à la fin. Dans le but de diffuser la Loi, ma vie durant, comme un seul homme, et également, à ma mort, de voir le Buddha, je déclare maintenant, pour ma part, retourner en mon pays [le Japon], à mille myriade de lieues du Continent par la mer. Le nombre de mes années a dépassé la soixantaine, et il m'est inutile d'espérer revoir ce monde-ci [Sahā : de patience]. En conséquence de quoi je joins ce livre sur la Pratique et le vœu qui résout les doutes sur la Terre pure, et je copie ce Exposé sur la naissance 
dans la Terre pure, en faisant le vœu de faire un avec le refuge sur la Contrée où l'on nourrit le bien-être. Ainsi donc, mon esprit est entièrement à s'accorder aux desseins du Buddha, et sans faute prendra pour voie d'y observer ses pensées.

L'an trois de l'ère Jiading [1210], grande année frère aîné du cheval-métal, le jour de la fin de la retraite d'été,

Résidant au Pavillon de l'enseignement du Tiantai de Chaoguo, dans la préfecture de Jixing, dans le département de Huading. Calligraphié par le moine Beifeng, Zongyin.

Le 13 du $3^{e}$ mois de la $3^{e}$ année de Karoku [1227], grande année frère aîné du feu-sanglier, le moine héritier de sa Loi, Shunjō, a copié à nouveau l'Exposé sur la Terre pure du rien-que-pensée transmis par Beifeng.

C'est avec révérence que je le donne au seigneur, l'ancien régent de Kujō [Michiie], pour que, ensemble, nous allions naître dans la Contré de l'Ouest de la seule pensée, en faisant le serment de voir le Buddha Amida de la nature originelle.

Le moine qui est allé chez les Song pour transmettre la Loi, Junshō, copié avec respect.

\section{Postface au Commentaire sur l'Homélie au Buddha Amitāyus de Jiedu des Song ${ }^{241}$}

Jadis, lorsque je résidais en Chine, j'ai vu les pratiquants des actes purs réciter à l'envi les paroles d'homélie au maître en discipline Dazhi ${ }^{242}$, mais ils ignoraient qu'il en existait un commentaire du maître de l'école Zhuoan ${ }^{243}$. Parmi les textes que Ryōyū a rapportés, je suis par hasard tombé sur celui-ci. Je souhaite le graver immédiatement sur planche afin d'en répandre la divulgation. Il se trouva deux moines, Kakujū et Jōkō ${ }^{244}$, qui à l'ordinaire fixaient leur pensée sur la Direction de l'Ouest [sur la Terre pure d'Amida] et qui, soudain, ont vu ce texte. Ils en conçurent de l'admiration et, abandonnant leurs biens purs, demandèrent à un artisan de le graver sur planche. Ils firent le vœu de le donner aux gens afin qu'ils puissent mettre en évidence leur nature foncière, qui n'est rien-que-pensée, pour monter de ce fait immédiatement dans le Domainc aux joyaux [de la Terre pure].

$\mathrm{Au}$ Japon, le $3^{\mathrm{e}}$ jour du $9^{\mathrm{e}}$ mois de la troisième année, kinoto- $i$, de l'ère Kenpō [1215],

Paraphé avec respect par Shunjō, moine qui s'est rendu en Chine afin de transmettre la Loi [au Japon], au Pavillon de l'Ouest pour la bodhi précieuse à l'Est de la Capitale.

241. Nous avons suivi le texte, d'après la version de Shōryō du Rinzan Henjō.in, en date de 1692 (Genroku 5), éditée dans Ishida, Shunjō risshi, p. 407. L'Homélie même, de 240 caractères distribués sur dix lignes, est de Lingzhi Yuanzhao (1048-1116), et le Commentaire, en un volume, est de Jiedu 城度: (actif en 1174-1189).

242. Lingzhi Yuanzhao.

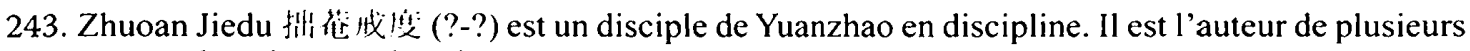
ouvrages sur la naissance dans la Terre pure.

244. Kakujū 染珄:, Jōkōo 浮光. 


\section{BIBLIOGRAPHIE}
Abréviations
DNBZ Collection complète des auvres du bouddhisme japonais [Dainihon bukkyo zensho 大日本佛教全書]
DNS Matériaux historiques du Grand Japon [Dainihon shiryō 大日本史料]
IBK Études d'indologie et de bouddhologie [Indogaku bukkyōgaku kenkyū 印度學佛教學研究]
MSS Matériaux sur le révérend Myōe [Myōe shōnin shiryō 明惠上人資料]
NDZ Canon du bouddhisme japonais [Nihon daizōkyō 日本大藏經]
NST Collection sur la pensée japonaise [Nihon shisō taikei 日本思想体系]
TSD Canon bouddhique de l'ère Taishō [Taishō shinshū daizōkyō 大正新 修大藏經]
ZGSRJ Collection thématique de matériaux historiques, Suite [Zoku Gunsho ruijū 續郡書類従]
ZZ Canon bouddhique de Kyōto, Suite [Manji zokuzōkyō 內續藏經]

Akamatsu, Toshihide 赤松俊秀,

1984 Histoire du Sennyūji [Sennyūjishi 泉涌寺史], deux volumes, Kenkyūhen 硎究篇, Shiryōhen 資料篇 [Études et Matriaux], Kyōto, Hōzōkan 法藏館.

ANZU, Motohiko 案津素彦 et UMEDA, Yoshihiko 梅田義彦

1968 Dictionnaire du shintō [Shintō jiten 神道辭典], Ōsaka, Hori Shoten 堀書店. Miroir des provinces de l'Est [Azumakagami 吾妻鏡], Kokushi taikei 國史大系, 5 volumes.

GYŌNEN 凝然 [1240-1321]

1977 Actes du saint Enshō [Enshō shōnin gyōjō 圓照上人行状], Tōdaiji Kyōgakubu 東大寺教学部, Tōdaiji Toshokan 東大寺図書館, Nara.

Eто, Chōei 江藤澂英, (éd.)

1924 Recueil sur l'éclaircissement du sens et la progression de la pratique [Myōgi shingyōshū 明義進行集], Chūgai Shuppan 中外出版, Kyōto.

FRANK, Bernard

2000 Amour, colère, couleur. Essais sur le bouddhisme au Japon, Paris, Collège de France, Institut des hautes études japonaises.

FuJıTA, Shunkyō 滕田俊教

1972 «Biographie du maître en discipline Shunjō » [ «Shunjō risshi no denki » 俊芿律師の伝記], dans Ishida (éd.), 1972, p. 281-302.

GIRARD, Frédéric

1990 Un moine de la secte Kegon à l'époque de Kamakura, Myōe (1173-1232) et le "Journal de ses rêves ", coll. "Publications de l'École française d'Extrême-Orient» n 160 , Paris, EFEO. 
2005 «Quête et transmission des reliques de la Chine au Japon au XIII ${ }^{\mathfrak{e}}$ siècle », dans Philippe Borgeaud et Youri Volokhine (éd.), Les objets de la mémoire. Pour une approche comparatiste des reliques et de leur culte, actes de colloque (Genève, 25-26 octobre 2003), coll. « Studia Religiosa Helvetica », Berne, Peter Lang - Société suisse pour la science des religions, p. 149-179.

IsHIDA, Jūshi 石田充之 (éd.)

1972 Recherches sur la formation du bouddhisme de Kamakura: le maître en discipline Shunjō [Kamakura bukkyō seiritsu no kenkyū: Shunjō risshi 鐮倉佛教の研究: 俊芿律師], Kyōto, Hōzōkan 法蔵館.

JoüON DES LONGRAIS, Frédéric

1965 Tashi. Le Roman de celle qui épousa deux empereurs : Nidai no Kisaki (1140-1202), Tōkyō-Paris, Maison Franco-Japonaise, Institut de recherches d'histoire étrangère.

LAMOTTE, Étienne

1949 Le Traité de la Grande Vertu de Sagesse de Nāgārjuna (Mahāprajnāpāramitāsástra), V tomes, Université de Louvain, Bibliothèque du Muséon/ Publications de l'Institut Orientaliste de Louvain, volumes 18,2,18,12,24, Louvain, Institut Orientaliste, Publications Universitaires (réimpr. 19661980).

Marsone, Pierre

2002 Aux origines du Zen, édition bilingue, commentée et annotée du Kōzen gokoku ron d'Eisai (1143-1215), Paris, You Feng.

MinowA, Kenryō 莶輪顕量

1995 «Les conceptions de Shunjō relatives au code disciplinaire - Du point de vue de l'auto-ordination et de la réception commune des trois ensembles de règles » [ « Shunjō no kairitsu shisō - jisei to sanju tsūju no kanten kara » 俊仍の戒律思想一自誓と三聚通受の観点から], Indogaku Bukkyōgaku Kenkyū, 14[1], (décembre), p. 92-95.

1999 Recherches sur la restauration des règles disciplinaires à Nara (début du Moyen Âge) [Chūsei shoki-Nanto kairitsu fukkō no kenkyū 南都戒律復 與の研究], Kyōto, Hōzōkan 法蔵館.

MochIzUKı, Shinkō 望月信亨

1924 Le Recueil sur l'éclaircissement du sens et la progression de la pratique de Shinzui et le sens de l'invocation d'Amida sans méditation ["Shinzui no Myōgi shingyōshū to mukan shōmyōgi » 信瑞の明義進行集と無觀稱 名義], dans Etō 1924 (appendice, 24 pages).

NAKAJIMA, Etsuji 中島悦次

1969 Commentaire complet à " Mes Humbles Vues » [de Jien 慈圓] [Gukanshō zenchūkai 愚管抄全註解], Tōkyō, Yūseidō Shuppan.

NAKAO, Ryōshin 中尾良信

1982 «Les écoles Zen et Disciplinaires au début de l'époque de Kamakura » [《Kamakura shoki no zenshū to risshū » 鎌倉初期の禅宗と律宗], Indogaku Bukkyōgaku Kenkyū, 31 [1], (décembre), p. 207-209. 
NōTomi, Jōten 納富常天

1974 《Shunjō et Dōgen» [ Shunjō to Dōgen » 俊芿乘と道元], Indogaku Bukkyōgaku Kenkyū, 23[1], (décembre), p. 123-129.

Ōtani DAIGAKu BUNGAKUSH KENKYūKaI 大谷大學文學史研究會

2001 Le Recueil sur l'éclaircissement du sens et la progression de la pratique. Réédition photomécanique [Myōgi shingyōshū eiin.honkoku 明義進行 集.影印.翻刻], Kyōto, Hōzōkan 法藏館.

Généalogies des familles nobles et basses [Sonpi bunmyaku 尊卑分脈], Kokushi taikei 國史大系, 5 tomes.

TAGA, Munehaya多賀宗隼

1972 Eisai [Eisai 栄西], Jinbutzsu sōsho 人物叢書, Yoshikawa kōbunkan 吉川 弘文官, Tōkyō.

Tsuchihashi, Shūkō 土橋秀高

1969 《Le système disciplinaire de Shunjō » [«Shunjō no rissei » 俊芿の律制], Indogaku Bukkyōgaku Kenkyū, 17[2], (mars), p. 28-32.

VANDERMEERSCH, Léon

1965 La Formation du Légisme, Recherche sur la constitution d'une philosophie politique caractéristique de la Chine ancienne, coll «Publications de l'École française d'Extrême-Orient » $n^{\circ} 56$, Paris, EFEO.

VERSCHUER, Charlotte von

2001 "Le moine Shunjô (1166-1227) : sa jeunesse et son voyage en Chine ", $B E F E O, 88$, p. 161-189. 